\title{
Primary marine aerosol emissions: size resolved eddy covariance measurements with estimates of the sea salt and organic carbon fractions
}

E. D. Nilsson ${ }^{1}$, E. M. Mårtensson ${ }^{1,2}$, J. S. Van Ekeren ${ }^{3}$, G. de Leeuw ${ }^{4,5}$, M. Moerman ${ }^{4}$, and C. O'Dowd ${ }^{6}$

${ }^{1}$ Atmospheric Science, Department of Applied Environmental Science (ITM), Stockholm University, 10691 Stockholm, Sweden

${ }^{2}$ Department of Meteorology, Stockholm University, 10691 Stockholm, Sweden

${ }^{3}$ Laboratory of Atmospheric Chemistry, Paul Scherrer Institute, 5232 Villigen PSI, Switzerland ${ }^{4}$ TNO, Defence, Security and Safety, P.O. Box 96864, 2509 JG, The Hague, The Netherlands ${ }^{5}$ Climate and Global Change Unit, Research and Development, Finnish Meteorological Institute, 00560 Helsinki/Department of Physical Sciences, Helsinki, P.O. Box 64, 00014 University of Helsinki, Finland

${ }^{6}$ Atmospheric Science Research Group/Environmental Change Institute, Department of Experimental Physics, National University of Ireland, Galway, University Road, Galway, Ireland

Received: 17 August 2007 - Accepted: 1 September 2007 - Published: 12 September 2007 Correspondence to: E. D. Nilsson (douglas.nilsson@itm.su.se)
ACPD

Primary marine aerosol emissions: size, sea salt and organic

E. D. Nilsson et al.

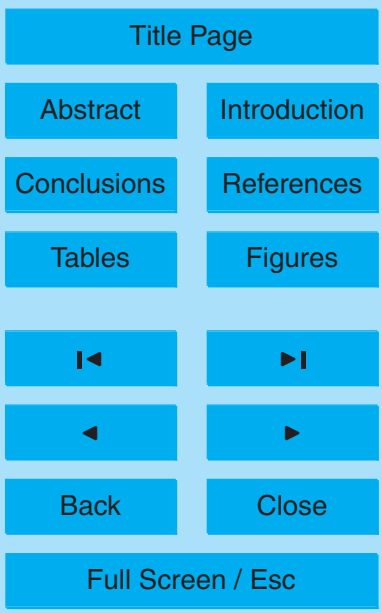

Printer-friendly Version

Interactive Discussion 


\section{Abstract}

Primary marine aerosol fluxes were measured using eddy covariance (EC), a condensation particle counter (CPC) and an optical particle counter (OPC) with a heated inlet. The later was used to discriminate between sea salt and total aerosol. Measurements

5 were made from the $25 \mathrm{~m}$ tower at the research station Mace Head at the Irish west coast, May to September 2002. The aerosol fluxes were dominated by upward fluxes, sea spray from bubble bursting at the ocean surface. The sea salt aerosol number emissions increased two orders of magnitude with declining diameter from 1 to $0.1 \mu \mathrm{m}$ where it peaked at values of $10^{5}$ to $10^{7}$ particles $\mathrm{m}^{-2} \mathrm{~s}^{-1}$. The sea salt emissions increased at all sizes in the wind range 4 to $22 \mathrm{~ms}^{-1}$, in consistency with a power function of the wind speed. The sea salt emission data were compared to three recent sub micrometer sea salt source parameterisations. The best agreement was with Mårtensson et al. (2003), which appear to apply from 0.1 to $1.1 \mu \mathrm{m}$ diameters in temperate water $\left(12^{\circ} \mathrm{C}\right)$ as well as tropical water $\left(25^{\circ} \mathrm{C}\right)$. The total aerosol emissions were independent 15 of the wind speed below $10 \mathrm{~ms}^{-1}$, but increased with the wind above $10 \mathrm{~ms}^{-1}$. The aerosol volume emissions were larger for the total aerosol than for the sea salt at all wind speeds, while the sea salt number emissions approached the total number emissions at $15 \mathrm{~ms}^{-1}$. It is speculated that this is caused by organic carbon in the surface water that is depleted at high wind speeds. The data are consistent with an internal aerosol mixture of sea salt, organic carbon and water. Using the aerosol model by Ellison et al. (1999) (a mono-layer of organic carbon surrounding a water-sea-salt brine) we show that the total and sea salt aerosol emissions are consistent. This predict that the organic carbon fraction increase with decreasing diameter from a few \% at $1 \mu \mathrm{m}$ over $50 \%$ at about $0.5 \mu \mathrm{m}$ to about $90 \%$ at $0.1 \mu \mathrm{m}$, in consistency with simulta25 neous chemical data by Cavalli et al. (2004). The combined models of Mårtensson et al. (2003) and Ellison et al. (1999) reproduce the observed total aerosol emissions and offer an approach to model the organic sea spray fraction.

\section{Primary marine aerosol emissions: size, sea salt and organic}

E. D. Nilsson et al.

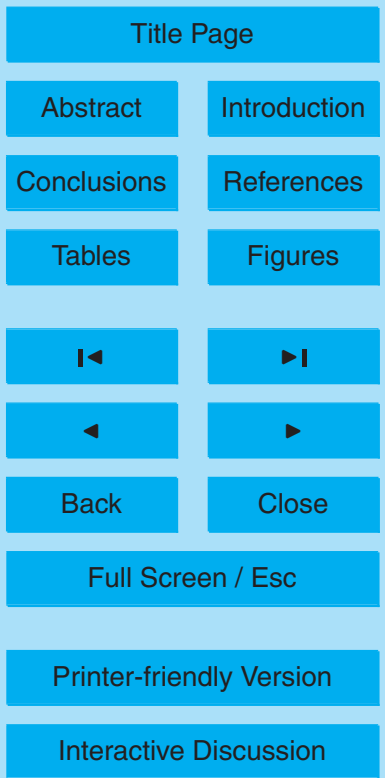




\section{Introduction}

\subsection{Background}

Small droplets are ejected into the atmosphere when bubbles burst at the sea surface in the white caps formed by breaking waves. This influences the ocean-to-atmosphere

5 flux of water, heat, sea salt, organic compounds, pollutants, and gases. If the resulting particles would consist only of sea salt then they would be very good cloud condensation nuclei (CCN). However, besides sea salt, the primary marine aerosol also has an organic component. The organic material may have been dissolved in the surface water, or been present in the surface water as an emulsion (with micelles), on the water surface as a thin film of surfactants, or as biological particles (bacteria, algae etc.) suspended in the water. Rising bubbles collect and concentrate surface-active organic molecules and bacteria. Organic molecules tend to concentrate at the water-air interface of the bubbles (Donaldson and Anderson, 1999), and this effect is enhanced by the presence of salts in the water. The recognition that bubble mediated droplets concentrate and transfer organic compounds from the ocean surface into airborne droplets has led to the recent hypothesis that life originated in primary marine aerosol particles rather than in the ocean itself (Donaldson et al., 2004), and that surface active organic molecules on liquid droplets of water-sea-salt-organic-solutions where responsible for the creation of cellular walls while larger and larger organic molecules and finally DNA formed in the droplet solutions in the pristine (low oxygen, high UV-radiation) atmosphere (Ruiz-Bermejo et al., 2007).

In the present ocean-atmosphere-system organic molecules may result from natural biogenic production, but there is also a contribution from human activities (e.g. SaintLouis and Pelletier, 2004). Estimates suggest that a large fraction of the marine aerosol 25 is organic (Novakov et al., 1997; O'Dowd et al., 2004; Cavalli et al., 2004). It has been assumed that much of this organic aerosol is secondary and formed by condensation, nucleation or in cloud processes, e.g. Finlayson-Pitt and Pitts (1997), from precursors of continental, often anthropogenic origin. Although it has been known for a long time

\section{Primary marine aerosol emissions: size, sea salt and organic}

E. D. Nilsson et al.

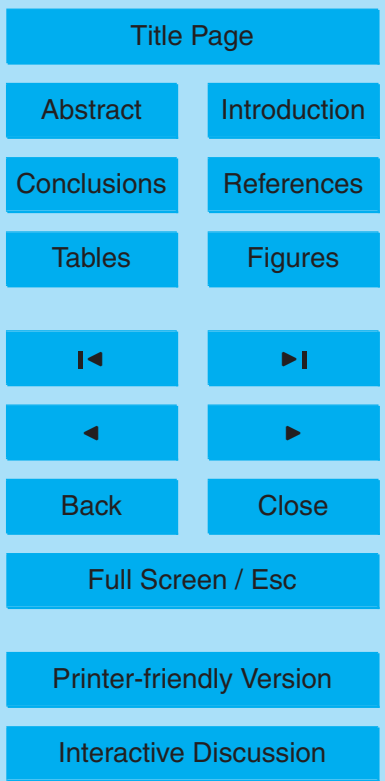


that there is a source of primary organic aerosol from the ocean, this source has not been quantified, and its relative importance compared to gas-to-particle conversion is unknown. At least part of this organic aerosol is water soluble and hygroscopic (Matsumoto et al., 1998; O'Dowd et al., 2004) and thereby potential CCN. Very little is 5 known about the exact composition of this organic fraction, and even less about chemical reactions that may take place in this aerosol. Recently Anastasio and Newberg (2007) showed for example that $\mathrm{OH}$ production in sea spray may be as large as in gas phase.

The primary marine aerosol may have in principle a natural source, but it cannot 10 be studied separately from anthropogenic aerosols and climate change. In the atmosphere the primary marine aerosol particles will age and mix externally with other aerosols, such as anthropogenic soot and sulphate aerosols. Coagulation, condensation and cloud processing will mix the primary marine aerosol internally with other anthropogenic or natural components that have secondary sources, such as ammo15 nia or sulphate. Due to such transformations, after some time in the atmosphere, the effects of the primary marine aerosol source cannot be separated from that of anthropogenic aerosols. The sea salt aerosol has a large influence on the atmospheric sulphur cycle (Chameides and Stelson, 1992), and it influences the climate effects of the natural and anthropogenic sulphate aerosol (O'Dowd et al., 1999). Even primary marine particles that are too small to initially act as CCN (below $\sim 100 \mathrm{~nm}$ diameter) may give a substantial CCN contribution due to the growth and ageing processes, for example through biogenic secondary marine sulphate (Pierce and Adams, 2006). In this way, the primary marine aerosol determines the number concentration, while secondary sources add mass and help with CCN formation through growth. It has also been suggested that climate change may influence the primary marine aerosol production significantly (Latham and Smith, 1990).

Anthropogenic (man-made) aerosol particles influence the earth albedo and climate directly by backscattering of solar radiation (Kiehl and Briegleb, 1993), and indirectly by acting as ice nuclei (IN) or cloud condensation nuclei (CCN), which will increase the

\section{Primary marine aerosol emissions: size, sea salt and organic}

E. D. Nilsson et al.

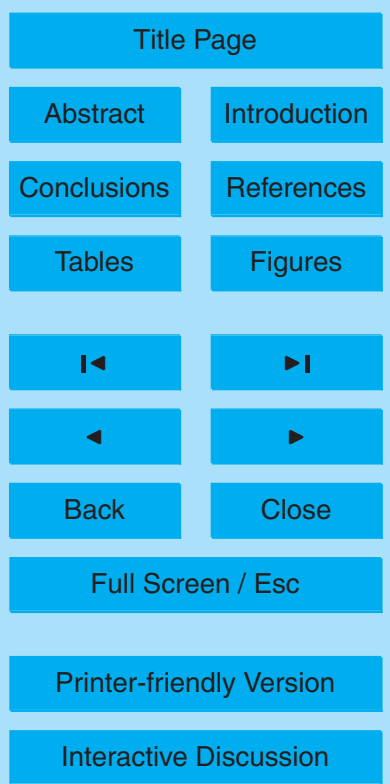

\section{8}


albedo and lifetime of the clouds (e.g. Boucher and Loman, 1995; Albrecht, 1998). The aerosol climate effect is the most uncertain part of the anthropogenic climate forcing (IPCC, 2001, 2007). In recent years more details has been added to the aerosol codes used in global models in order to improve future climate predictions. Simulations with 5 such models show that CCN production is sensitive to how the aerosol sources are represented (e.g. Guelle et al., 2001; Adams and Seinfeld, 2002; Pierce and Adams, 2006). Since the CCN concentration is crucial to determine the indirect aerosol climate effect, large uncertainty results from our incomplete understanding of the aerosol source processes by number, size, magnitude and temporal/spatial distribution. Sea 10 salt particles are the dominant sub-micrometer scatterer in most remote ocean regions, and a possible CCN source for the large areas of low marine clouds. It is therefore essential to understand the primary marine aerosol source, and to be able to quantify this source with realistic parameterisations in the climate models.

While field measurements show the presence of a large fraction of sea salt particles 15 in the sub-micrometer aerosol (e.g. O'Dowd and Smith, 1993; Murphy et al., 1998; Nilsson et al., 2001), sea salt source parameterisations available up to recently neglects this fact. Even when this is recognised, parameterisations has often been based on extrapolations of super-micrometer data (see for example Gong, 2003 who extrapolates Monahan et al., 1986) or scaled to observed atmospheric concentrations rather than 20 actual particle production (see Vignatti et al., 2001 who makes use of the concentration data and parameterisation from O'Dowd et al., 1993), or they just extend a little bit into the sub micrometer range. The recent exceptions are Mårtensson et al. (2003) and Clarke et al. (2006), which present sub-micrometer parameterisations that cover fully two decades of the sub micrometer (down to $\sim 10 \mathrm{~nm}$ ) based on modern aerosol in25 strumentation, and specifically for sea salt, see next section for details. Finally, almost nothing is known about the source amplitude and behaviour of the organic fraction. As a result, there is no parameterisation that describes the separate contributions of sea salt (SS) and organic carbon (OC). This constitutes an important gap in our knowledge since the CCN production will be dominated by sub-micrometer particles and the abil-

\section{Primary marine aerosol emissions: size, sea salt and organic}

E. D. Nilsson et al.

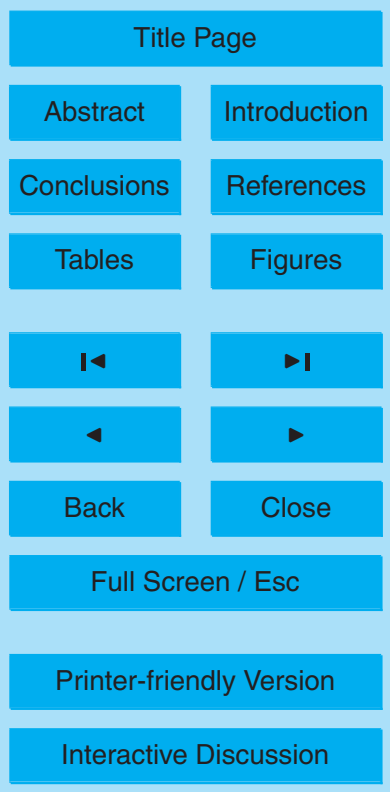


ity of these particles to become CCN will depend on their size, composition, and the degree of internal or external mixing.

\subsection{Recent quantifications and parameterisations of the sea spray source}

The first successful direct in situ flux measurements (using the eddy covariance (EC) 5 method) of the primary marine aerosol source were made over the Norwegian Sea, Barents Sea and Arctic Ocean (Nilsson et al., 2001). The aerosol flux over the open sea was found to be an exponential function of the wind speed

$\overline{N^{\prime} W^{\prime}}=10^{0.16} \bar{U}-1.4910^{6}\left(\mathrm{~m}^{-2} \mathrm{~s}^{-1}\right)$

for a dry diameter $D_{p}>10 \mathrm{~nm}$, where $\overline{N^{\prime} W^{\prime}}$ is the upward aerosol net flux and $\bar{U}$ the 10 mean horizontal wind speed at $10 \mathrm{~m}$ height. This number flux was larger than previous indirect estimates from field data and previous parameterisations, presumably because it includes a large fraction of sub-micrometer particles. Geever et al. (2005) reported similar results with the same approach. Log linear (exponential) fits have also been used to describe the dependency of sea salt aerosol number or mass concentration on wind speed in numerous publications. The most refined analysis is O'Dowd et al. (1993). Two modes appeared to contribute to the aerosol flux in the Nilsson et al. (2001) data, centred at about $100 \mathrm{~nm}$ and $1 \mu \mathrm{m} D_{p}$. This agree very well with later similar independent bubble tank experiments, in that the $100 \mathrm{~nm}$ mode prevail in both artificial (salt) water and real sea water (Mårtensson et al., 2003; Tyree et al., 2007; Keene et al., 2007).

Throughout this paper, the new size resolved fluxes will be compared with three recent source parameterisations that include the full sub micrometer range (about two decades) (Mårtensson et al., 2003; Gong, 2003; Clarke et al., 2006) and refer to the older parameterisation by Monahan et al. (1986). These will be denoted MÅ03, GO03, CL06 and MO86, respectively. There are several other source parameterisations in the literature that covers only the upper part of the sub-micrometer range, which have excluded them from this study.

Primary marine aerosol emissions: size, sea salt and organic

E. D. Nilsson et al.

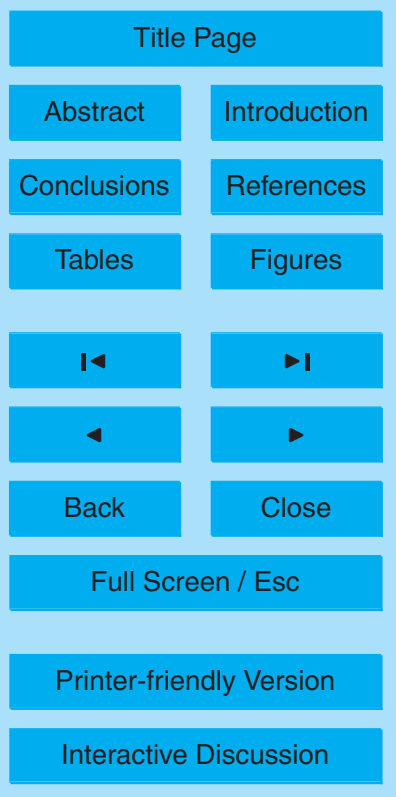


Bubble bursting and primary marine aerosol production were simulated in the laboratory by MÅ03 and measured with modern aerosol instrumentation from $18 \mathrm{~nm}$ to $20 \mu \mathrm{m}$ $D_{p}$. The experiment was repeated with different salinity and water temperatures. MÅ03 found the largest aerosol production in a mode centred at about $80-100 \mathrm{~nm} D_{p}$ with a 5 long slope towards a second weaker mode at about $2.5 \mu \mathrm{m} D_{p}$. From the experiments a size resolved parameterisation of the aerosol source flux was derived. The parameterisation has the form

$$
\frac{d F_{0}}{d \log D_{p}}=\Phi\left(T_{w}, D_{p}\right) W(\bar{U})\left(\mathrm{m}^{-2} \mathrm{~s}^{-1}\right)
$$

where $d F_{0} / d \log D_{p}$ is the source number flux per ocean area and size increment, and $W$ is the white cap area fraction following Monahan and O'Muircheartaigh (1980) as

$$
W=3.8410^{-4} \bar{U}^{3.41}
$$

The source flux per white cap area and size increment $\Phi$ is composed of three water temperature $\left(T_{w}\right)$ dependent polynomial functions. Equations (1) and (2) represents two main approaches to the form of the wind dependency of the primary marine aerosol 15 source, which are both widespread in the literature: either an exponential relationship as in Eq. (1) or a power law as in Eq. (2). In difference to the MO86-experiments MÅ03 produced bubbles continuously, primarily to reduce the discrete counting errors. We could see from the beginning that MÅ03 produced a realistic total number of particles when compared to the total sea spray emission flux from eddy covariance (Nilsson et al., 2001), but it is not until in this current study that we have been able to evaluate its size distribution.

CL06 derived a size resolved sub-micrometer sea-salt emission, based on the gradient in vertically distributed concentration measurements (subtracting the background aerosol from the aerosol produced in the surf zone, similar to de Leeuw et al., 2000), with a complex approach in order to normalise the production to the changing white cap area in the surf zone. Their method lead directly to a size resolved emission

\section{Primary marine aerosol emissions: size, sea salt and organic}

E. D. Nilsson et al.

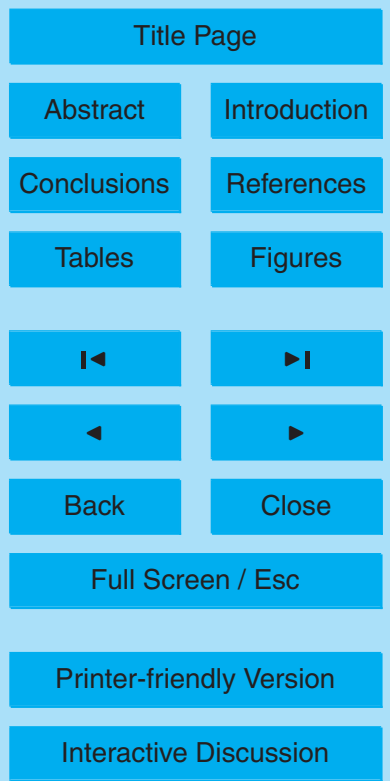


parameterisation, without any intermediate aerosol fluxes. CL06 is like MÅ03 based on polynomial equations with different coefficients in three different size ranges, but without the sea surface water temperature (which stayed close to $25^{\circ} \mathrm{C}$ in the CL06 experiments).

5 GO03 is an extension of the MO86 source parameterisation, which it is limited to particles $>0.8 \mu \mathrm{m}$ radius at $80 \% \mathrm{RH}$ (corresponding to $\sim 0.9 \mu \mathrm{m}$ dry $D_{p}$ ). MO86 is still used in many models (for example Guelle et al., 2001; Grini et al., 2002; Gong et al., 2002; Pierce and Adams, 2006; or Koch et al., 2006) and new (modified) parameterisations are still formulated on basis on it (for example Gong, 2003 or Cafreey et al., 2007).

10 There is a complicated confusion regarding the size range and $\mathrm{RH}$ for which MO86 is valid: for example Gong et al. (2002) claim that it is based on data from $\sim 0.4 \mu \mathrm{m}$ dry diameter (while Gong et al. (1997) cite the correct applicable range), Spracklen et al. (2005) claim that it is valid down to $0.2 \mu \mathrm{m}$ diameter, Pierce and Adams (2006), Koch et al. (2006) use it down to $0.1 \mu \mathrm{m}$ diameter, Guelle et al. (2001) use it down to 150.062 dry diameter, and Grini et al. (2002) cite correctly the right application limit, but still use it down to $0.03 \mu \mathrm{m} 80 \% \mathrm{RH}$ radius in lack of better. Many investigators are aware of its limitations, but also of the accumulating evidence for sub micrometer sea spray. This is clearly why GO03 was developed.

The MO86 experimental data was presented in Monahan et al. (1982) that specify 20 the $\mathrm{RH}$ for the experiment as $56-67 \%$. The MO86 is usually interpreted as defined for the radius at $80 \% \mathrm{RH}$, but it is actually not clearly stated in the paper. In an accompanying paper (in the same book on "Oceanic whitecaps") Spillane et al. (1986) gives another version of the parameterisation (with other coefficients) specified for the radius at $80 \% \mathrm{RH}$ in the size range $0.8-10 \mu \mathrm{m}$ radius. It is interesting to notice that while the 25 instrumentation behind MO86 was limited to the super micrometer range, a few years later Cipriano et al. (1987) made similar experiments in the same tank, using in addition an early CPC. Cipriano et al. (1987) concluded that the particle number production was dominated by sub-micrometer particles with a much larger total production than MO86, much closer to MÅ03. Furthermore, while there is no specification of $T_{w}$ in Monahan et

\section{Primary marine aerosol emissions: size, sea salt and organic}

E. D. Nilsson et al.

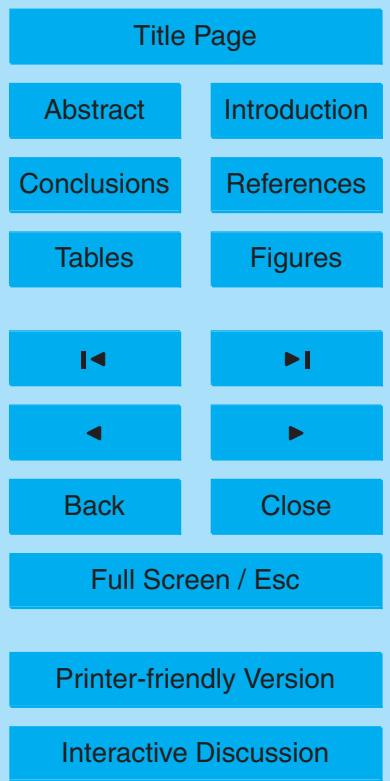

13352 
al. $(1982,1986)$ and $T_{w}$ is not included in MO86, Bowyer et al. (1990) used the same tank as MO86 and showed in agreement with MÅ03 an increase in the larger particle production with increasing $T_{w}$ and a decrease for the small particles with increasing $T_{w}$. It is possible that MO86 could have been extended into the sub-micrometer and

5 could have included the effect of changing $T_{w}$, had all the tank data been used. Hence there is no discrepancy between the data produced in the tank used for Monahan and his associates and that used for MÅ03. MÅ03 could be seen as the experimental extension of MO86, with detailed sub micrometer instrumentation. As the MÅ03 is not valid in most of the super micrometer, they complement each other and can be used 10 together (see for example Foltescue et al., 2005).

GO03 modify the MO86 equations in a way that includes a tuning parameter $\Theta$ that can reshape the source size dependency within very generous ranges. GO03 have been used in global models with values for $\Theta$ that is justified because they give the best or least bad agreement with some bulk observations of sea salt mass concentration 15 (the most common value for $\Theta$ is 30, see for example Gong, 2003 and Spracklen et al., 2005). Tuning a parameterisation in that way implies that we cannot trust the result for calculations of the aerosol forcing, effects on clouds or its response on a changing climate. The parameterisation is not independent from the choice of and set up of the model and may be sensitive to differences in wind fields, advection scheme, dry or wet deposition etc. However, the intention of Gong (2003) was:"...this adjustable parameter is especially useful to optimise the parameterisation in the future when detailed sub micron measurements become available." With the new in situ eddy covariance size resolved sub micrometer sea salt aerosol fluxes presented in this paper, we can try to follow this intention.

25 The two studies by MÅ03 and CL06 represent two different experimental approaches to the problem: laboratory experiments and gradient measurements in the field, respectively. What they have in common is detailed sub-micrometer size spectra and source parameterisations covering two decades of the sub-micrometer range, and they both deal exclusively with sea salt. In this study we use a third approach, in situ EC fluxes,

\section{Primary marine aerosol emissions: size, sea salt and organic}

E. D. Nilsson et al.

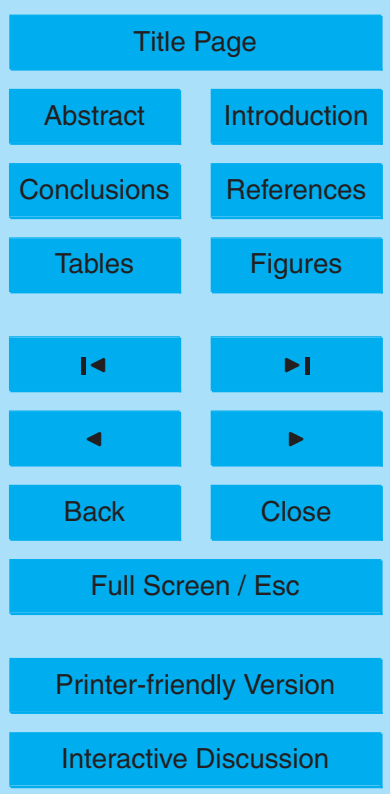


which is a more direct estimate of the sea spray emissions. We will let the results determine if any of the existing parameterisations is valid and to decide what direction to go next. Unlike the earlier EC fluxes in Nilsson et al. (2001) and Geever et al. (2005), we will present a detailed size resolution for the EC fluxes and separate fluxes of par5 ticles of different volatility in order to achieve some indirect information of the chemical characteristics of the particle flux.

\section{Method and site}

\subsection{Eddy covariance (correlation)}

The vertical aerosol number flux was calculated with the eddy covariance technique. If 10 we separate the aerosol number concentration $N$ and the wind speed $w$ in mean and turbulent fluctuations $N=\bar{N}+N^{\prime}$ and $w=\bar{W}+w^{\prime}$ where overbar denotes temporal mean and the turbulent deviations from the mean and use the Reynolds decomposition we can write the vertical flux $w N=\bar{w} \bar{N}+\overline{w^{\prime} N^{\prime}}$ where $\bar{w} \bar{N}$ is the mean wind transport by low frequency large-scale transport and $\overline{w^{\prime} N^{\prime}}$ is the turbulent eddy transport in the vertical direction. The turbulent transport is a covariance between fluctuations in vertical wind and concentration. Within the atmosphere surface layer it equals the net transport that results from both sinks and sources at the surface, provided that all transformation processes are negligible. Sensible heat $\overline{W^{\prime} T^{\prime}}$ and momentum $\overline{W^{\prime} u^{\prime}}+\overline{W^{\prime} V^{\prime}}$ are calculated in a similar manner.

For this study the flux $\overline{w^{\prime} N^{\prime}}$ was calculated over periods of $30 \mathrm{~min}$. The fluctuations $W^{\prime}$ and $N^{\prime}$ were separated from the mean by linear de-trending, which also removes the influence of low frequency trends. Prior to the calculation of $\overline{w^{\prime} N^{\prime}}$ the wind vectors where rotated to achieve a zero $\bar{w}$, and the aerosol data was shifted in relation to the wind data to correct for the time lag in the sampling line (calculated from the maximum correlation).

\section{Primary marine aerosol emissions: size, sea salt and organic}

E. D. Nilsson et al.

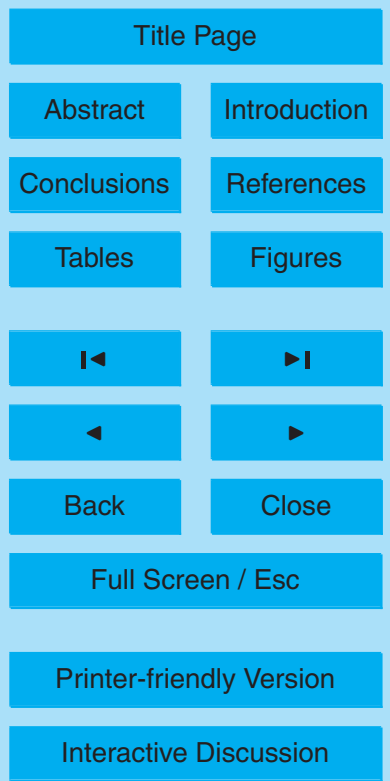


The 3-D wind components and temperature were measured with a Gill R3 research ultrasonic anemometer, and logged at $20 \mathrm{~Hz}$. To measure the total aerosol number concentration $\left(D_{p}>11 \mathrm{~nm}\right)$ we used a Condensation Particle Counter (CPC), model 5 TSI 3762, which was logged through a pulse-to-analogue voltage converter and two of the Gill R3 external analogue signal input lines, also logged at $20 \mathrm{~Hz}$. The aerosol was sampled just beneath the sonic head through a $3 \mathrm{~m}$ long sampling line of $1 / 4$-inch stainless steel. The sampling flow through the CPC was $3.0831 \mathrm{~min}^{-1}$ with a bypass flow of $4 \mathrm{Imin}^{-1}$ and a total flow in the sampling line of $\sim 7 \mathrm{Imin}^{-1}$ (laminar). An Optical

10 Particle Counter (OPC), model PMS ASASP-X, was used to measure the aerosol number concentration in 31 size classes from $100 \mathrm{~nm}$ to $10 \mu \mathrm{m}$ at $1 \mathrm{~Hz}$, using a separate $1 / 4$-inch stainless steel $4 \mathrm{~m}$ long sampling line with a flow of $0.120 \mathrm{Imin}^{-1}$ (laminar).

Part of time the air sampled by the OPC was heated to $300^{\circ} \mathrm{C}$ with a controlled heater system just before the OPC, which is a well established way to determine the 15 volatility of the aerosol (see for example O'Dowd et al., 1993 and Brooks et al., 2002). At this temperature only the non-volatile aerosol fraction should reach the OPC. In the clean marine environment, sea salt should be the dominant non-volatile aerosol component. Furthermore, when considering fluxes, sea salt should be the only nonvolatile component that is positively correlated with the vertical wind (positive = upward fluxes). Other non-volatile components may be present in small amounts, e.g. soot or crustal material, but these will have a smaller and negative covariance with the vertical wind and cause small negative deposition fluxes (see also discussion in Sect. 3.1). Neglecting the latter we refer to the non-volatile aerosol flux as the sea salt aerosol flux.

25 During other parts of the data set the air sampled for the OPC was heated more moderately (temperatures resulting in a relative humidity near or below $40 \%$, which should dry most aerosol particles). For this part of the data set, the particles that are positively correlated with the vertical wind (and hence have a source at the ocean sur-

\section{Primary marine aerosol emissions: size, sea salt and organic \\ E. D. Nilsson et al.}

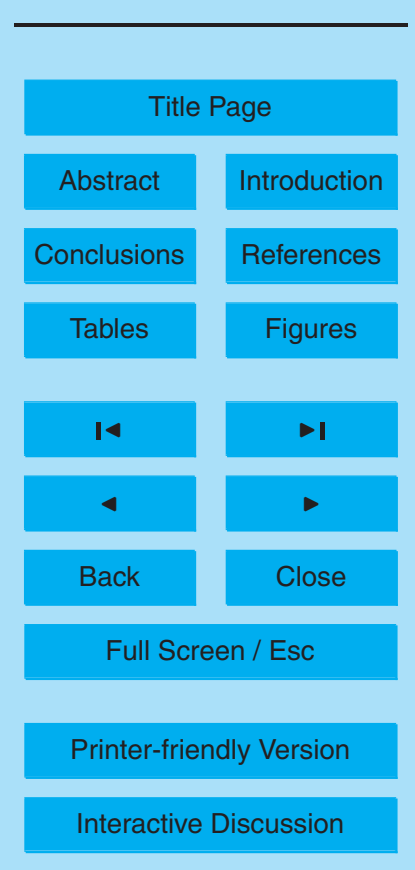


face) should consist of sea salt plus other more (semi) volatile chemical components originating from the ocean surface water. Such compounds would most likely be various forms of organic carbon. Semi-volatile organic carbon from other more distant up-wind sources would only have a weak and negative covariance with the vertical

5 wind contributing only with a small deposition flux (see Sect. 2.5.2). The same would apply to other aerosols that don't have a major primary marine particulate source, such as sulphate or ammonia, including all secondary aerosol components. We will call this the total flux, to distinguish it from the sea salt flux.

In this study, if not specifically stated, $D_{p}$ is the aerosol particle diameter as it was 10 measured by the OPC. For the heated air this should be the diameter of the remaining sea salt particles. These may be what remain after evaporation of other externally mixed particles, in which case they may be close to their original size (minus water), or size reduced sea salt residue of internally mixed particles. For the total aerosol, it should be the diameter of either internally mixed particles of sea salt and semi volatile 15 (organic) compounds, or the individual diameters of an external mixture of sea salt particles and organic particles, or both. Please note that we don't use the term "total aerosol" to denote the total number integrated over a larger size range. When we introduce sea salt emission parameterisations, we will apply them on dry sea salt particles. It is common in this field of research to use the diameter at $80 \%$ relative humidity, but 20 we don't for the simple reason that it is dependent on the assumption that the particles are pure sea salt particles and that their hygroscopic growth is known. Indeed, later in this study, we will show that this is not the case.

\subsection{Measurements period and site}

The data set used in this study was collected at the Mace Head research station at the 25 North-Atlantic coast of Ireland $\left(53^{\circ} 20^{\prime} \mathrm{N}, 09^{\circ} 54^{\prime} \mathrm{W}\right)$. The data were collected during the biologically productive season of 2002 starting with the QUEST 1 campaign and ending with the NAMBLEX campaign (Heard et al., 2006), i.e. 24 May to 27 September. The eddy-covariance system was mounted in the $22 \mathrm{~m}$ tower near the shore at the Mace

\section{Primary marine aerosol emissions: size, sea salt and organic}

E. D. Nilsson et al.

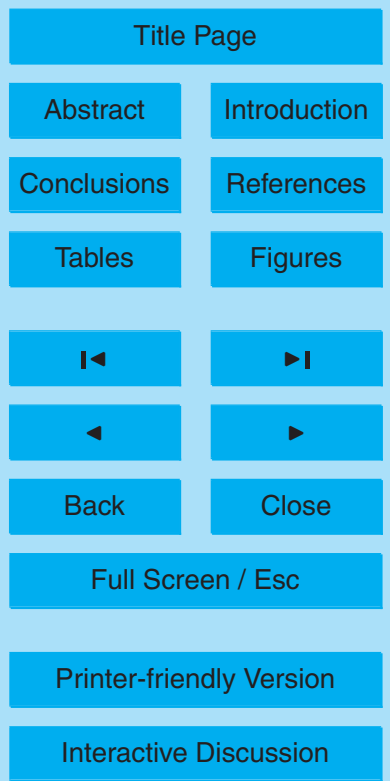


Head station approximately $50 \mathrm{~m}$ from the shore at high tide and $150 \mathrm{~m}$ at low tide. The sonic R3 head was located $25.5 \mathrm{~m}$ above the ground. The aerosol was sampled just beneath the sonic head.

Kunz and de Leeuw (2000) and de Leeuw et al. (2002) show that there is a sig5 nificant difference for measurements in the tower at 18 and $22 \mathrm{~m}$ with more influence of the internal boundary layer at the lower height. Also Geever et al. (2005) found an influence of low tide at $22 \mathrm{~m}$ in the same tower. In addition, Norton et al. (2006) found that increasing height meant less influence of the internal boundary layer, but came to the conclusion that already $15 \mathrm{~m}$ in the same tower was enough to avoid the 10 internal boundary layer at low tide. For the current study the results of the previous measurements at 18 and $22 \mathrm{~m}$ led to the decision to locate the ultrasonic anemometer and aerosol inlet even higher up, at $25.5 \mathrm{~m}$.

The panorama-photo in Fig. 1 , which covers a view of more than $180^{\circ}$, shows the rocky shorelines in the north and south and the sea to the west. We observed an 15 increase in roughness during low tidal periods and corresponding differences in the turbulent fluxes for the south sector and somewhat less for the north sector when the wind was coming almost parallel to the coastline towards the measurement tower. For the west sector, however, despite that low tide could be seen as a higher surface roughness, this could not be seen in the drag coefficient, or the momentum or aerosol fluxes.

20 This is in contrast to the previous measurements at 18 and $22 \mathrm{~m}$, which suggests that the measurements from $25.5 \mathrm{~m}$ that we present here as intended were made above the internal boundary layer, and that the elevated position was enough to avoid local effects at low tide. It appears hence that the conditions for flux measurements from the west wind sector in onshore wind are close to open sea conditions. Based on these arguments, in the current study we use only data from the 220 to $300^{\circ}$ wind sector, guided by calculated roughness height, friction velocity and drag coefficients. This left in total 753 half hour periods of heated OPC fluxes/ sea salt aerosol fluxes from Julian Day 144 to 198, and 178 half hour periods of unheated OPC fluxes/total aerosol fluxes from Julian Day 157 to 252. After Julian Day 198 the OPC was broken for a long period

\section{Primary marine aerosol emissions: size, sea salt and organic}

E. D. Nilsson et al.

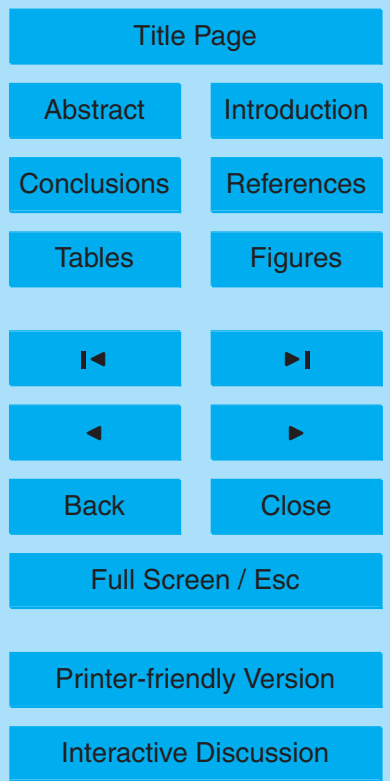


during July and August, and when it was restarted again, it could only be operated without the volatility heater.

\subsection{Corrections}

\subsubsection{Effects of limited instrumental frequency response}

5 The frequency response of the CPC and OPC is limited, and the first-order response time constant $\tau_{c}$ was $0.4 \mathrm{~s}$ for the CPC and $1 \mathrm{~s}$ for the OPC (it was sampled at $1 \mathrm{~s}$ intervals). The underestimation of the flux depends on the frequency of the turbulence, which is determined by the observation level $z(25.5 \mathrm{~m})$, mean horizontal wind speed $\bar{U}$ and stratification $z / L$, where $L$ is the Monin-Obukov length. The underestimation in 10 the flux can according to (Buzorius et al., 2003) be estimated as

$$
\frac{F_{m}}{F}=\frac{1}{1+\left(2 \pi n_{m} \tau_{c} \bar{U} / z\right)^{\alpha}},
$$

with $\alpha=1$ for $\mathrm{z} / \mathrm{L}>0$ (stable stratification) and $\alpha=7 / 8$ for $\mathrm{z} / \mathrm{L} \leq 0$ (neutral and unstable stratification). The normalized frequency, $n_{m}$, equals 0.085 for $\mathrm{z} / \mathrm{L} \leq 0$ and

$$
n_{m}=2.0-\frac{1.915}{1+0.5\left(\frac{z}{L}\right)} \text {. }
$$

for $z / L>0$. The aerosol fluxes presented in this work has been corrected according to
Eq. (3) and (4). The correction was on average $25 \%$ of the measured net aerosol flux.

\subsubsection{Losses of particles in the sampling tube}

The loss and penetration of particles in the OPC sampling line has been estimated with the model by K.-C. Hsieh (Particle Tech., Inc.) and B. Y. H. Liu (Univ. of Minnesota), which includes gravitation settling, Brownian-Diffusion and impaction in laminar and

Primary marine aerosol emissions: size, sea salt and organic

E. D. Nilsson et al.

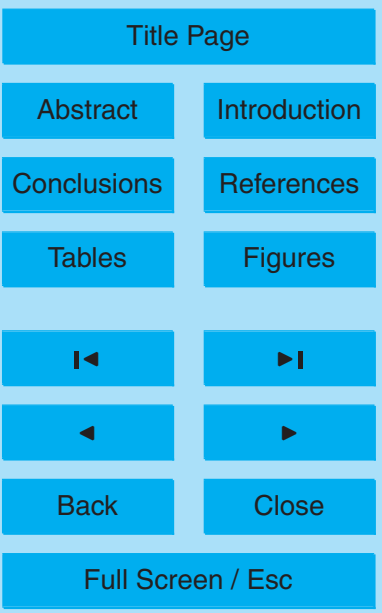

Printer-friendly Version

Interactive Discussion 
turbulent flow for a combination of straight and curved tube sections. This allowed for a realistic representation of the actual sampling line, including two curved sections. In this exercise, one has to consider that if the aerosol would be an internal mixture of semi-volatile and non-volatile compounds, the heated sea salt aerosol particles most 5 certainly were larger while they travelled with the sampling flow through the tube. Since the size change did not take place until in the controlled heater in between the sampling line and the OPC, the aerosol kept the same size in the sampling line independent of if we measured total or sea salt aerosol fluxes. It shall be shown later on that indeed the average sea salt aerosol flux appears to be shifted in size a factor $\sim 3.7$ below the 10 total aerosol flux (see Sect. 3.7). We have used this to estimate the aerosol spectra in the sampling tube while we sampled the non-volatile aerosol, to allow us to calculate the penetration fraction. The penetrating fraction of the aerosol sampled for the total aerosol flux was $50 \%$ at $2.5 \mu \mathrm{m} D_{p}$ and $10 \%$ at $4 \mu \mathrm{m} D_{p}$. The penetrating fraction for the sea salt aerosol was $50 \%$ at $0.75 \mu \mathrm{m}$ heated $D_{p}$ and $10 \%$ at $1.1 \mu \mathrm{m}$. At sizes 15 smaller than 2.5 and $0.75 \mu \mathrm{m}$ the penetrating fraction rapidly increase to $<5 \%$. At $0.1-0.3$ and $0.1-1 \mu \mathrm{m} D_{p}$, respectively, more than $90 \%$ of the particles penetrated the tube.

\subsection{Errors}

\subsubsection{Uncertainty due to discrete counting}

20 Following to Buzorius et al. (2003), the uncertainty in the flux, due to the discrete counting can be expressed as

$\delta\left(\overline{w^{\prime} N^{\prime}}\right)=\frac{\sigma_{w} \bar{N}}{\sqrt{\bar{N} Q \Delta t}}$

where $\sigma_{w}$ is the standard deviation of the vertical wind, $\bar{N}$ is the aerosol number concentration averaged over the sampling period $\Delta t$ (in our case $30 \mathrm{~min}$ ), and $Q$ is the 13359

\section{Primary marine aerosol emissions: size, sea salt and organic}

E. D. Nilsson et al.

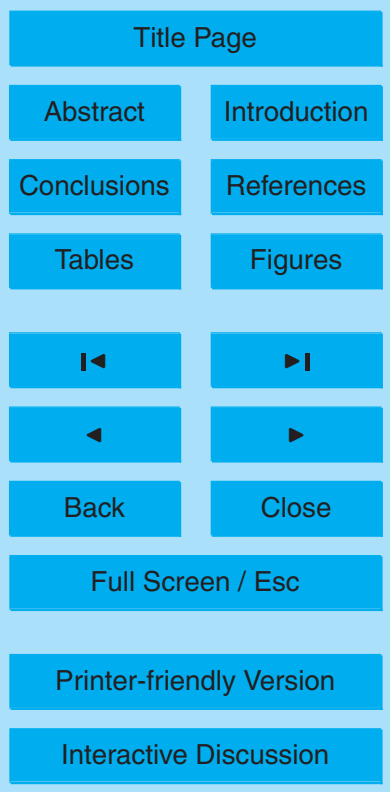

EGU 
sampling volume flow rate through the particle counter. When considering relative errors, high turbulence and number concentrations usually corresponds to high aerosol number fluxes, so the relative error may actually decrease with increasing $\bar{N}$ and $\sigma_{w}$, and vice verse.

$5 \quad$ In the current data set, the errors range on average from $13 \%$ at $110 \mathrm{~nm}$ to $70 \%$ at $3.75 \mu \mathrm{m} D_{p}$ for the total aerosol flux. For the sea salt aerosol flux the corresponding errors where $33 \%$ and $76 \%$. At larger sizes the error grows rapidly above $100 \%$. For the $\mathrm{CPC}$, this error is negligible due to the much higher number counts.

\subsubsection{Influence of deposition fluxes in the surface layer}

10 Our measurements include the range in which the aerosol dry deposition has a minimum (which cause the so called accumulation range or accumulation mode). Previously in Nilsson et al. (2001), we corrected for the contribution from Brownian diffusion, interception, impaction and sedimentation to the upward CPC net fluxes with the help of a deposition model, in order to derive emission fluxes. This was necessary 15 mainly because of the large Brownian diffusion for particles $<100 \mathrm{~nm}$ diameter. Brownian diffusion, as well as the other deposition processes, are small for particles in the $\sim 100-500 \mathrm{~nm}$ diameter range. For diameters $>0.5 \mu \mathrm{m}$ the deposition velocity due to sedimentation begins to increase, but in this size range the aerosol number concentration also decrease rapidly, so the resulting dry deposition contribution to the net aerosol flux remains small. Our estimates show that for the OPC fluxes it is never above 5\%, and in most of the size range of interest less than $1 \%$. For this reason, we have chosen to ignore this error.

In summary: The aerosol fluxes we present below have been corrected for the limited frequency response and for particle losses in the sampling line, as described above. 25 The errors presented in Figs. 3, 4 and 7 are the discrete counting errors calculated from Eq. (5). We have estimated that the deposition fluxes in the surface layer can be neglected throughout the OPC range that we use. Hence, we can from now on consider the observed corrected net fluxes as an approximation for emission fluxes.

\section{Primary marine aerosol emissions: size, sea salt and organic}

E. D. Nilsson et al.

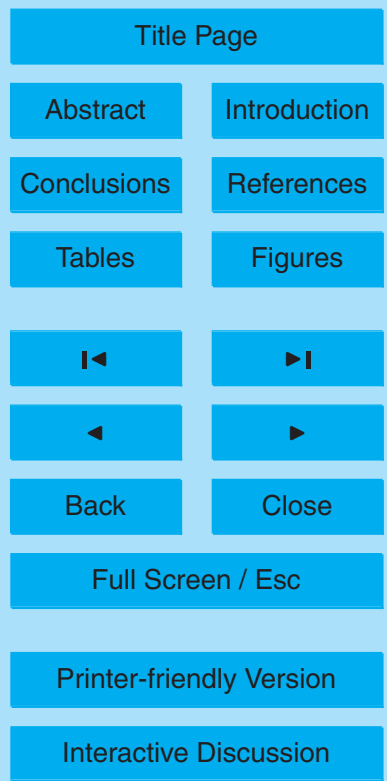




\section{Results and discussion}

\subsection{Emission vs. deposition net fluxes}

Even in the absence of sources, there will still be natural variation and measurement errors resulting in some apparent positive and upward fluxes. In such a case there 5 should be a negative downward median flux. If the flux frequency distribution despite the negative median extends a toe over to the positive side, this is not a proof in support of an aerosol source. On the other hand, it is in principle impossible to measure emission fluxes separately from deposition. In the presence of a source, net fluxes are formed both from sources and sinks in such a way that one mode form on the positive 10 and another one on the negative side, each with a distribution in both directions, with a minima in between the two modes, even though they partly overlap. If there isn't, there either is no source, or it is too week to be distinguished from the negative deposition fluxes, given the precision of your system.

Figure 2 shows the frequency distribution for the current number fluxes integrated over the full OPC size range, for the sea salt and total aerosol. In both cases there are two well-defined modes and a clear minimum at zero. Upward fluxes dominated in both cases, both in magnitude and frequency: $75 \%$ of both total and the sea salt aerosol fluxes were positive. Of course, each positive flux, even though it is dominated by the emission flux, contains some influence from deposition, see above in Sect. 2.5.2. The overall median value for the aerosol number fluxes was positive also for the CPC, but the preference for upward fluxes was less pronounced $(58 \%)$. This indicates that deposition may have played a more significant role for the net fluxes due to increasing Brownian diffusion below $100 \mathrm{~nm}$ diameter.

\subsection{Temporal variability}

25 Figure 3 shows one day of measurements in Mace Head from noon 9 June to noon 10 June (Julian days 160 and 161). This $24 \mathrm{~h}$ period started with southerly winds, which

\section{Primary marine aerosol emissions: size, sea salt and organic}

E. D. Nilsson et al.

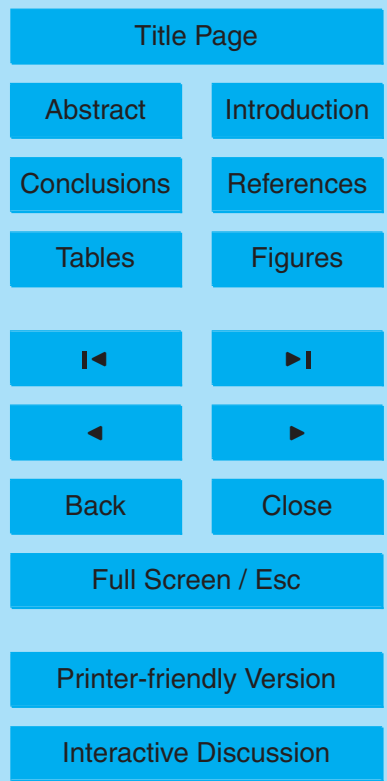


rapidly turned (in one hour) over to south-west and passed $220^{\circ}$, entering the wind sector that we selected for further analysis, turned further to west-south-west (in four hours) and then stayed between west-south-west and west for the rest of the period. Fig. 3a shows the total aerosol number flux for $D_{p}>11 \mathrm{~nm}$ (from the CPC), which varies 5 from $10^{6}$ to $10^{7}$ particles $\mathrm{m}^{-2} \mathrm{~s}^{-1}$. The aerosol number sea salt flux integrated for $D_{p}>100 \mathrm{~nm}$ (from the OPC) follows a similar pattern (in Fig. 3b), but the magnitude is only one fifth of the total aerosol number flux in Fig. 3a. If we compare with the average horizontal wind speed in Fig. $3 g$ there is an obvious correlation between aerosol source fluxes and the wind speed.

10 The simple Nilsson et al. (2001) parameterisation (Eq. 1) agrees within a factor 2-3 with the measured total aerosol emission fluxes in Fig. 3a, but predict too high emissions at high wind speed. The more complex parameterisation for the size resolved sea salt number flux by MÅ03 agrees approximately with both the flux according to the CPC and the OPC (when Eq. 1) is integrated down to 11 and $100 \mathrm{~nm}$, respectively) in 15 Fig. $3 a$ and $b$, for this specific case. The CL06 source parameterisation predicts too low emissions compared to the flux $>11 \mathrm{~nm} D_{p}$ in Fig. 3a, but for the OPC flux $>100 \mathrm{~nm} D_{p}$ in Fig. 3b, CL06 predict emissions in fair agreement with the observations and so close to MÅ03 that we haven't included CL06 in the figure. The predictions by GO03 depend entirely on the choice of the arbitrary tuning parameter $(\Theta)$. For the emissions $>10 \mathrm{~nm}$ 20 $D_{p}$ a value of $\Theta=11$ predicts almost exactly the same flux as MÅ03 (which is why it is not shown in Fig. 3a) and in fair agreement with the observations. Values below this (see examples for $\Theta=22$ and $\Theta=44$ ) predicts too low emissions. On the other hand, for emissions $>100 \mathrm{~nm} D_{p}$ a value of $\Theta=22$ gives the best agreement (close to both MÅ03 and CL06).

25 The sea salt aerosol number flux for two specific size channels in the OPC with the mean diameter 0.11 and $0.475 \mu \mathrm{m} D_{p}$ is presented in Figs. $3 \mathrm{c}$ and d. It is evident from these figures that while the smallest of the size channels very well follows the fluxes $>11$ and $100 \mathrm{~nm}$ diameter in Figs. $3 a$ and b, and the wind in Fig. 3f, this is less clear for the largest size channel, presumably due to the larger uncertainty caused by low

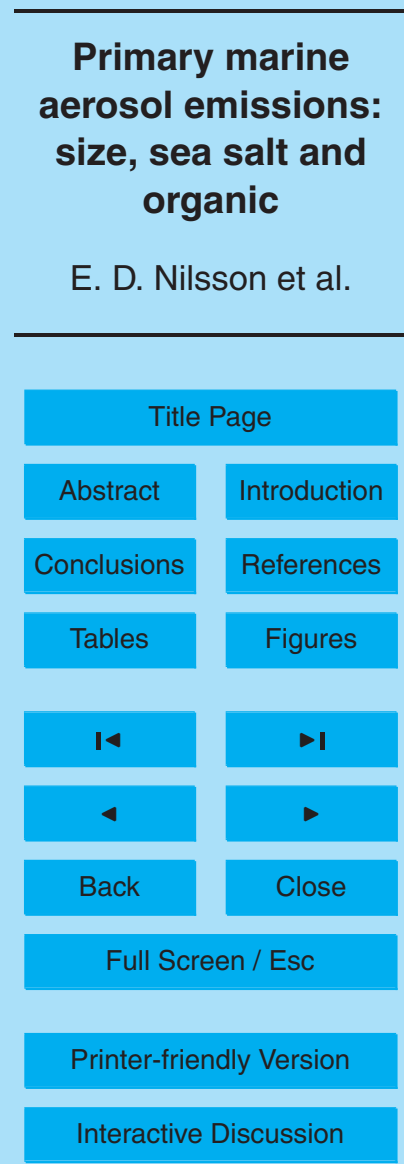


number counts (see error bars), which hide much of the true variation. In this channel and those even larger it is in practise often difficult to follow the changes from one sample to the next.

Figures $3 e$ and $3 f$ describes the micrometeorological conditions, which can be sum5 marized in two words: near neutral $(-0.1<z / L<0.1)$. This is typical for most of the data set. It is worth noticing in Fig. 3h that the aerosol number concentrations of either the CPC or the OPC do not follow the wind speed variations. The CPC aerosol number concentration is even anti-correlated to the wind speed, despite that the CPC aerosol number fluxes in Fig. $3 a$ are well correlated to the wind speed.

\subsection{Size resolved sea salt aerosol emissions}

The EC flux data we have presented are the first direct in situ flux measurements with detailed enough sub micrometer size resolution to be able to compare the resulting aerosol flux size distribution to the magnitude and shape of the three recent source parameterisations that cover more or less fully two decades of the sub micrometer.

\subsubsection{Specific cases}

Figure 4 demonstrates four individual half hourly sea salt aerosol number flux size spectra: examples of wind speeds of $5,10,15$ and $20 \mathrm{~ms}^{-1}$. We can see how the observed fluxes increase with the wind speed. Except for a few values the fluxes are positive (emissions). The figures also show the parameterised sea salt flux from MÅ03, CL06 and GO03. For all but the lowest wind speed in Fig. 4a MÅ03 predict the observed flux size distributions very well. There is a larger scatter around the predicted size distribution for the $5 \mathrm{~ms}^{-1}$ example, and the observed fluxes are generally larger than the MÅ03 prediction for this wind speed. Some of the relatively larger scatter should originate from the discrete counting errors. CL06 and GO03 have the same problem with the low wind speed as MÅ03. In addition, for the higher wind velocities, CL06 tend to underestimate the fluxes for the smaller particles and overestimate the

\section{Primary marine aerosol emissions: size, sea salt and organic}

E. D. Nilsson et al.

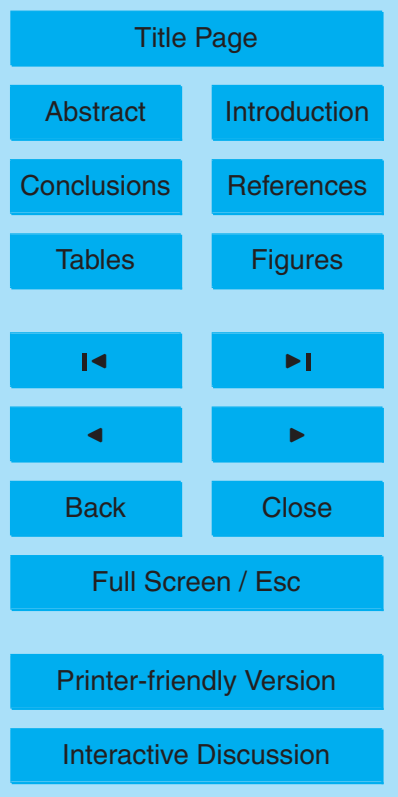

EGU 
fluxes for the larger particles, having a smaller slope than both observations, G003 and MÅ03. This deviation is larger than the counting errors. GO03 tend to agree as well as MÅ03, but this conclusion is only firm above $\sim 0.5 \mu \mathrm{m} D_{p}$. For the smaller particles, GO03 is dependent on a tuneable parameter $\Theta$. The arbitrarily chosen value $\Theta=22$ 5 that we use in Fig. 4 appears to work well for this selection of data, but differs from the value previously recommended by GO03, and cause GO03 to deviate from the data as well as MÅ03 below $\sim 0.2 \mu \mathrm{m} D_{p}$, which may be why GO03 need a different value to successfully predict the CPC fluxes in Fig. 3a (see further comparison in Sect. 3.4).

In agreement with Figs. $3 c$ to $3 d$, we can see that the relative errors tend to increase 10 with increasing particles size. Low wind speed is also causing larger relative errors. We saw in Fig. 3d for the larger size channel how the increasing counting errors made it difficult to distinguish small variations along a time sequence, the large differences in flux over size (the flux change about two orders of magnitude over about one diameter decade) are still significantly larger than the errors, see Fig. 4.

$15 \quad 3.3 .2$ Average conditions

In Fig. 5 we will use the median sea salt flux size distribution from the OPC data, and the median aerosol flux in between the lower cuts of the CPC and the OPC (11-100 nm $D_{p}$ ). The CPC aerosol flux is not heated, and therefore not strictly a sea salt flux. It is however reasonable to assume that the amount of particles that may shrink to below $2011 \mathrm{~nm}$ is insignificant compared to the total aerosol number flux in this size range. All parameterisations shown in Fig. 5 will be applied at the median wind speed of our sea salt flux data $\left(9.75 \mathrm{~ms}^{-1}\right)$ and for MÅ03 the median water temperature $\left(12^{\circ} \mathrm{C}\right)$.

The number fluxes show a steep decrease with increasing size: more than 2 orders of magnitude from the sub to the super micrometer ranges, just like the previous exam25 ples. The conclusion from Fig. 4 applies on the average as well: the flux is changing so much with size that it allows conclusions regarding the shape of the aerosol flux size distribution despite the large errors in the upper end of the size range.

We have seen that the MÅ03 compares well with our eddy covariance sea salt

\section{Primary marine aerosol emissions: size, sea salt and organic}

E. D. Nilsson et al.

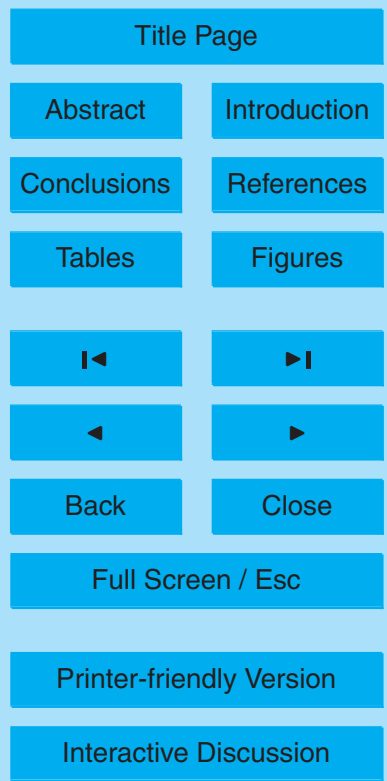


aerosol fluxes from 0.1 to $1.1 \mu \mathrm{m} D_{p}$, for the median values and at various wind speed, see Figs. 3 and 4 , but only for the $T_{w}$ values of our data set (on average $12^{\circ} \mathrm{C}$ ). Comparing our sea salt flux size spectra directly to the source according to CL06 does not fall out well, see Figs. 3, 4 and 5, except in the middle size range $200-500 \mathrm{~nm} D_{p}$. 5 However, CL06 showed that their parameterisation compared very well with the MÅ03 at tropical water temperatures $\left(25^{\circ} \mathrm{C}\right)$, see also Fig. 5. There is a significant difference between the 12 and $25^{\circ} \mathrm{C}$ emissions. At $1 \mu \mathrm{m} D_{p}$, the tropical case gives $\sim 300 \%$ more particles. Below $100 \mathrm{~nm} D_{p}$ the observed flux over the temperate North Atlantic case gives almost twice as many particles. Applying the CL06 parameterisation outside the tropics in models may introduce an unnecessary error, and the difference between CL06 and MÅ03 at high latitudes will be large, see Pierce and Adams (2006). Instead, one should perhaps consider CL06 not primarily as an alternative source parameterisation, but as a tropical sea salt emission data set, which validates the MÅ03 parameterisation for the tropics.

15 GO03 underestimates the emission of particles in the 0.4 to $0.9 \mu \mathrm{m} D p$ by up to $\sim 100 \%$ for temperate water (compare with MÅ03 and the EC data) and 200\% for tropical water (compare with CL06 and MÅ03), see Fig. 6. Considering the errors, this difference may be just on the limit of being significant for the temperate case, but there is certainly a significant discrepancy for tropical waters, whatever $\Theta$ we choose. It can 20 be tuned to agree with the level and slope of the temperate EC-data of the current paper or with MÅ03 in the $150-400 \mathrm{~nm} D_{p}$ range, but not with the tropical curves that have a smaller slope, and will at the same time $(\Theta=22)$ greatly underestimate the production below $150 \mathrm{~nm} D p$ compared to all other data or parameterisations (compare with Figs. $3 a$ and $b$ where different values of $\Theta$ are needed to tune GO03 to the CPC and OPC based fluxes, respectively. It is unable to reproduce the shape of any of CL06 and MÅ03 in below $100 \mathrm{~nm} D_{p}$. If we tune it to produce the same magnitude of particles below $100 \mathrm{~nm} D_{p}(\Theta=11)$ it will predict too high particle formation above $100 \mathrm{~nm} D_{p}$ and peak too early compared to MÅ03 and CL06. The most commonly used value for $\Theta(30)$ underestimates all emissions below $\sim 200 \mathrm{~nm} D_{p}$ (not shown).

\section{Primary marine aerosol emissions: size, sea salt and organic}

E. D. Nilsson et al.

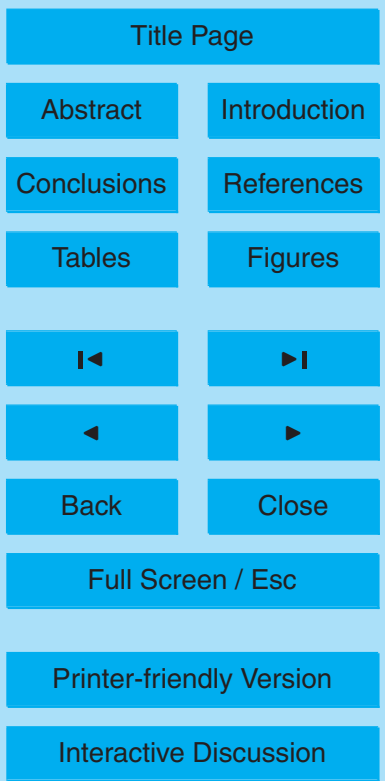

13365 
The shape of the GO03-equation is not compatible with the new experimental results, and we are unable to find one optimal value for $\Theta$.

Figure 6 also includes the lower and upper 25 and 75 percentiles of the observed sea salt aerosol fluxes, and the MÅ03 flux based on the 25 and 75 percentiles of 5 the observed wind speed for the corresponding data. Also the 25 and 75 percentiles agree well between measured fluxes and MÅ03, which indicates that the variation in the observed fluxes is also reproduced well by MÅ03. In summary, the MÅ03 parameterisation, which showed the best agreement with data in Figs. 3 and 4, agrees best with data also for the median flux in Figs. 5 and 6 . Comparison with the other param10 eterisations arrives with the same conclusions as before: CL06 have a too low slope, and GO03 agree well above $0.5 \mu \mathrm{m} D_{p}$, while the result for the smaller particles depends on the choice of $\Theta$ value. We consider the favourable comparison with our in situ sea salt flux measurements of both individual examples and the median and the percentiles as a validation of MÅ03 for a water temperature of $12^{\circ} \mathrm{C}$ from 0.1 to $1.1 \mu \mathrm{m}$ ${ }_{15} D_{p}$.

\subsection{Size resolved total aerosol fluxes}

Figure 7 shows the size resolved total aerosol number flux. It is constructed similarly to Fig. 4, except that the fourth example is missing as we had no data exactly at $20 \mathrm{~ms}^{-1}$. Furthermore, we have not included all parameterisations, only MÅ03, since this agreed 20 best with the observed sea salt aerosol emissions. The purpose of including the sea salt emissions of MÅ03 in the Fig. 7 is not to directly compare, since it should not be directly comparable to the total aerosol emission flux, but to have a measure of the level of the sea salt emission. The $15 \mathrm{~ms}^{-1}$ case is close to the sea salt parameterisation curve, although most data points fall slightly above the sea salt curve and the counting errors are mostly smaller than the difference. At $10 \mathrm{~ms}^{-1}$ however, the measurements are typically a factor $\sim 3$ above the sea salt curve, and at $5 \mathrm{~ms}^{-1}$, the discrepancy exceed the predicted sea salt emission fluxes a factor $\sim 100$. These examples are typical: at low wind speed the observed total flux greatly exceed the predicted sea salt

\section{Primary marine aerosol emissions: size, sea salt and organic}

E. D. Nilsson et al.

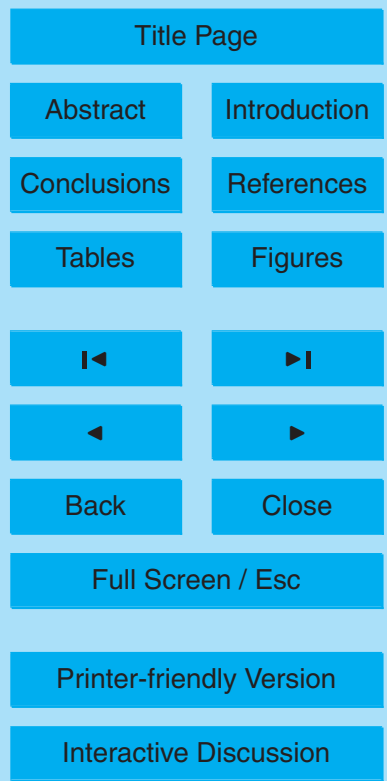

13366 
flux, at moderate wind the discrepancy decrease, but is still large, and at high wind speed it approach the MÅ03 sea salt curve.

\subsection{Wind speed influence}

The examples in Fig. 4 indicate that the sea salt flux is a strong function of wind speed, 5 and Fig. 8 show that this is indeed a general behaviour, which applies both for number and volume fluxes. The median, 25 and 75 percentiles of the observed sea salt fluxes show a steady increase with wind speed. We can also see in Fig. 8 that the total aerosol appears to be less wind dependent than the sea salt aerosol as seen when comparing Figs. 4 and 7, but on a generally higher level than these. Below $10 \mathrm{~ms}^{-1}$ the 10 aerosol emissions appear to be on a level that is independent of the wind speed. From $10-15 \mathrm{~ms}^{-1}$ the total aerosol flux increase with the wind speed. It can be seen in Fig. 8 how the total aerosol number emissions gradually approach the sea salt emissions. In difference to this, the total aerosol volume emissions remain larger than the sea salt volume emissions with increasing wind speed, keeping roughly the same ratio.

15 To achieve a comparable measure for how strongly the aerosol emissions depend on the wind speed at different diameters and to find the most representative measures of the aerosol flux and wind speed relationship we have calculated the correlation between $d \overline{w^{\prime} N^{\prime}} / d \log D_{p}$ and $\bar{U}$, either assuming an exponential relationship as in Eq. (1), or a power law as in Eqs. (2) and (3). An interesting difference appears between the sea salt flux and the total aerosol flux. For sea salt, the aerosol number flux is well correlated with the wind from $0.1 \mu \mathrm{m} D_{p}$ and up. For the total aerosol the correlation is much smaller below approximately $0.35 \mu \mathrm{m} D_{p}$. It appears that the total aerosol number emission is only wind dependent at $\bar{U}>10 \mathrm{~ms}^{-1}$ and only for $D_{p}>350 \mu \mathrm{m}$. For sea salt, any lower size limit must be found at diameter below $0.1 \mu \mathrm{m} D_{p}$.

25 The relatively constant total aerosol emissions at wind speed below $10 \mathrm{~ms}^{-1}$, followed by increased fluxes at wind speed above $10 \mathrm{~ms}^{-1}$, could be explained if there were a layer of water near the surface with higher concentration of organic matter (not

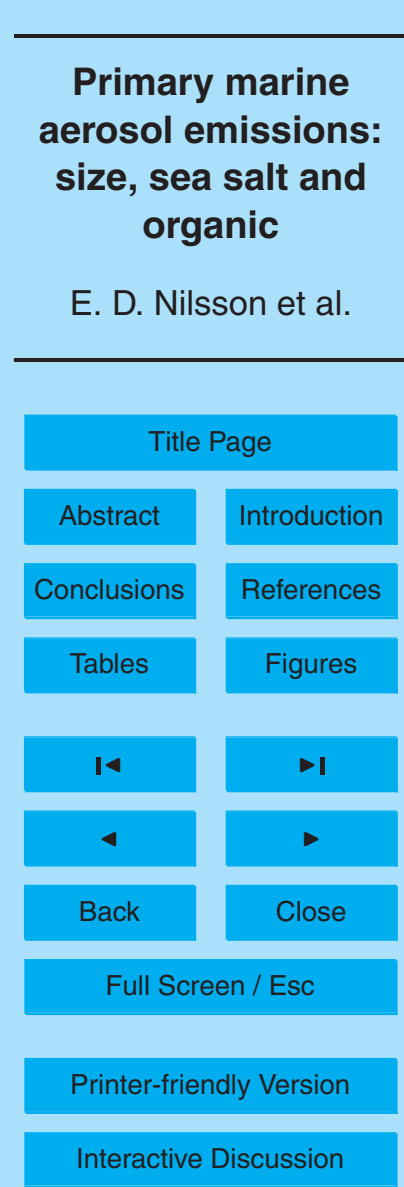


necessarily a so called surface film, but maybe an emulsion of water and organics) that was ruptured at higher wind speed or that was depleted from organic compounds. Below $10 \mathrm{~ms}^{-1}$, the aerosol would reflect more the organic content than sea salt, while above $10 \mathrm{~ms}^{-1}$, sea salt becomes gradually more important. Lacking water samples 5 we can only speculate.

We have calculated the curve fits between the wind speed and the integrated number flux for the size intervals that are well correlated to the wind speed. For the sea salt integrated from $100 \mathrm{~nm}$ to $1.1 \mu \mathrm{m} D_{p}$ the power law gave a fit of $\overline{W^{\prime} N^{\prime}}=0.495 \bar{U}^{3.41}$, with $r=0.677$ and the exponential law gave $\overline{w^{\prime} N^{\prime}}=10^{0.087} \bar{U}^{-1.405}$, with $r=0.645$. This is an 10 insignificant difference in the over-all correlation, despite that the power law has higher values for each size channel. The integrated average source flux was $5.6 \times 10^{5} \mathrm{~m}^{-2} \mathrm{~s}^{-1}$ (with an average wind speed at $10.0 \mathrm{~ms}^{-1}$ ). For the total aerosol emissions (excluding the sizes with low wind speed correlation below $\sim 0.3 \mu \mathrm{m} D_{p}$ ) the power law gave $\overline{W^{\prime} N^{\prime}}=0.236 \bar{U}^{3.41}$, with $r=0.663$ and the exponential law gave $\overline{W^{\prime} N^{\prime}}=10^{0.072} \bar{U}^{-1.658}$, with $15 r=0.442$, and an integrated source flux of $3.5 \times 10^{5} \mathrm{~m}^{-2} \mathrm{~s}^{-1}$ (the average wind speed was $8.3 \mathrm{~ms}^{-1}$ ). For the integrated total aerosol, the power law worked significantly better. It appears as the power law-expression using $\bar{U}^{3.41}$ is better correlated than the exponential relationship, especially for the sea salt fraction. If corrected to the same wind speed $\left(10 \mathrm{~ms}^{-1}\right)$, using the power law, the integrated source flux for the total 20 aerosol increases to $6.6 \times 10^{5} \mathrm{~m}^{-2} \mathrm{~s}^{-1}$. This is only $\sim 18 \%$ larger than the integrated sea salt emission number.

These results can be compared to Geever et al. (2005) who reported $\overline{w^{\prime} N^{\prime}}=$ $10^{0.097} \bar{U}^{-1.25}$ with a correlation of 0.75 for the entire OPC range (not heated and hence corresponding to our total aerosol flux). This fit is both starting at a higher zero wind level and has a steeper sloop with increasing wind speed, and Geever et al. (2005) also report a higher total emission at $10 \mathrm{~ms}^{-1}$ : in total $2 \times 10^{6} \mathrm{~m}^{-2} \mathrm{~s}^{-1}$, of which $50 \%$ in the OPC range, which is still $\sim 50 \%$ more than our integrated total aerosol number flux

\section{Primary marine aerosol emissions: size, sea salt and organic}

E. D. Nilsson et al.

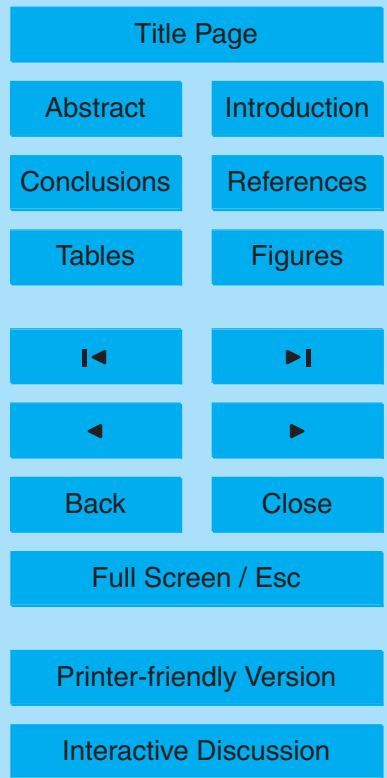


at the same average wind speed and $\sim 80 \%$ more than the integrated sea salt number flux. The difference may reflect differences in the selected data size or periods that may cause for example differences in the average wind speed or in the biology.

3.6 Total vs. sea salt flux: semi-volatile organic carbon aerosol emissions revealed

5 Figure 9 shows the average size resolved aerosol number and volume fluxes for both the total dry aerosol flux and the non-volatile fraction of the flux, together with the MÅ03 parameterisation. Because the total and non-volatile aerosol fluxes were not simultaneously measured, we must be considerate when comparing them. The samples are unequally distributed during the seasons with an emphasis of non-volatile heated sampling in the beginning (during the QUEST campaign), and of total aerosol samples during the later part of the measurement period. This cause the somewhat different average wind speed (10.0 and $8.3 \mathrm{~m} \mathrm{~s}^{-1}$, respectively for the sea salt and total aerosol fluxes). However, as the data set with the lower wind speed has the largest fluxes, and vice verse, the different wind speed cannot have caused the difference in fluxes, even 15 if we would assume a power law increase in emissions with increasing wind speed. On the contrary, it may have caused us to underestimate the differences. With this considered, we chose to take the MÅ03 parameterisation as a reference for comparison with both the total and the sea salt aerosol flux size distributions.

Through May to September 2002 the SeaWIFS observed Chlorophyll concentrations in the waters just west of Ireland and Mace Head that were unusually high (http://oceancolor.gsfc.nasa.gov/cgi/anomalies.pl), more than $0.5 \mathrm{mgm}^{-3}$, but the values suggests that the biological conditions were reasonable stable on a month-tomonth basis. At least it appears that our data set does not include data from before or after the biologically active season, and that there was no major systematic change between the two parts of the data sets.

In any case, it can be seen in Fig. 9 that the total flux is on average distinctly larger than the MÅ03 sea salt parameterisation, while the sea salt flux are on level with the MÅ03 parameterisation, at all sizes. This indicates that part of the aerosol that has a

\section{Primary marine aerosol emissions: size, sea salt and organic}

E. D. Nilsson et al.

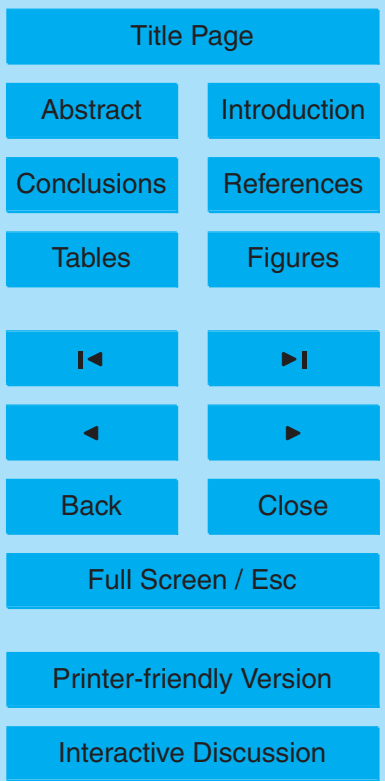


net source in the footprint of the flux system is lost when the air is heated. We must therefore carefully consider whether what we see is a total loss of externally mixed semi volatile particles, causing a shift in the number size distribution downward (reduced number in the heated air), or internally mixed particles that decrease in volume as they 5 lose semi volatile substances causing a shift of the size distributions to the left (smaller diameters) and downwards (less volume and diameter in the heated air).

\subsection{External or internal mixture?}

Figure 10a show the median total and sea salt aerosol volume flux, this time without the tube loss correction (see Sect. 2.4.2). Over most of the size range, both curves 10 increase with increasing diameter. However, the flux decrease with increasing size from 0.7 to $1.1 \mu \mathrm{m} D_{p}$ and from 2.5 to $4 \mu \mathrm{m} D_{p}$ for the sea salt and total aerosol volume flux, respectively. This is most likely caused by losses of particles in the sampling line and the diameter shift gives us a good indication of how much the aerosol scrunch in the controlled heating device. A diameter shift of a factor 3.7 gives the best over all fit, see 15 Fig. 10a. The corresponding curves with the tube loss correction are shown in Fig. 10b. Consider that the factor 3.7 is based on average emissions flux size spectra, and are hence an average. The shifted spectra do not agree as well at all diameters, which suggest that the volume mixing ratio may change with size, although the differences are near or smaller than the average errors. In Fig. 10, the curve that describes what remain of the total aerosol flux when shifted a factor 3.7 in size have been compensated for the differences in average wind in between the two data sets, sea salt and total aerosol, to exclude that part of the difference that could be due to differences in wind speed, although this is a minor effect.

Figure 8 show aerosol number emissions as functions of wind speed. Since the total aerosol number emissions are larger than the sea salt number emissions at all wind velocities below $15 \mathrm{~ms}^{-1}$, once could easily come to the conclusion that the semi volatile organic carbon and the sea salt are externally mixed, so that heating lead to the loss of a large number of purely organic particles. One must however realise that

\section{Primary marine aerosol emissions: size, sea salt and organic}

E. D. Nilsson et al.

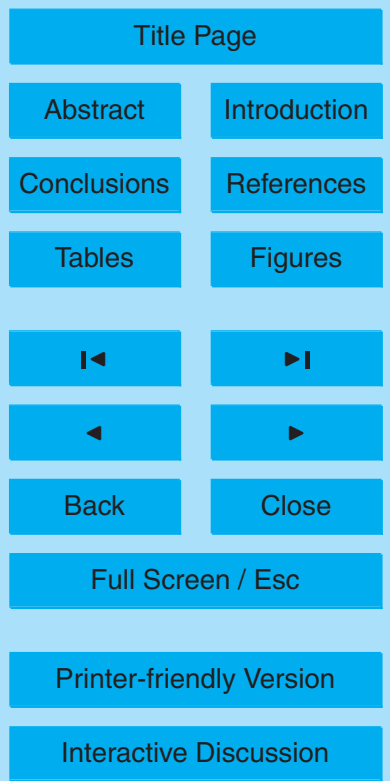


if the aerosol particles are instead an internal mixture, as suggested by Fig. 10, this implies that the remaining sea salt particles are not measured at the diameter at which they where emitted. Recall the large downward slope in number concentration with increasing diameter in the $0.1-1 \mu \mathrm{m} D_{p}$ range shown in Figs. 4 to 7 . If for example a $50.1 \mu \mathrm{m} D_{p}$ sea salt particle was originally 3 to 4 times larger, it is associated with an aerosol number emission flux several times smaller then the $0.1 \mu \mathrm{m} D_{p}$ particles in the total aerosol flux, which is enough to explain the smaller sea salt number emissions in Fig. 8. This makes the observed wind dependency fully compatible with an internally mixed aerosol.

10 An external mixture on the other hand would simply shift the total aerosol number emission flux size distributions from Fig. 10a down to form a sea salt flux. If one remove $4 / 5$ of the median total number flux (corresponding to four times more organic particles than sea salt particles) this produce a curve that roughly fall on the same level as the observed median sea salt aerosol flux, as long as we consider fluxes corrected for the tube losses. However, if we do this operation without the tube loss correction (in the way the particles were actually counted), the external mixture fails to explain the observed fluxes.

If both the non-volatile and semi volatile fractions of the aerosol flux originate from the bubble bursting at the water surface, they should probably appear as an internal mixture, at least if the surface water composition is spatially homogeneous on the scale of the size of the flux foot print $\left(\sim 1 \mathrm{~km}^{2}\right)$. If not, it would be necessary to envisage why the bubble bursting process should form sea salt and organic particles separately, or assume that the surface water has such variations in its composition within the flux foot print that some areas produce sea salt particles and some produce organic particles.

The similarity in the coefficients of the wind speed dependency presented in Sect. 3.5 support the assumption that the aerosol flux found in the sub micrometer sea salt aerosol flux and in the total flux are the same particle flux, except that the particles have changed size. These fluxes were originally integrated over the size intervals with the strongest correlation between wind speed and aerosol fluxes (above $\sim 0.35 \mu \mathrm{m} D_{p}$

\section{Primary marine aerosol emissions: size, sea salt and organic}

E. D. Nilsson et al.

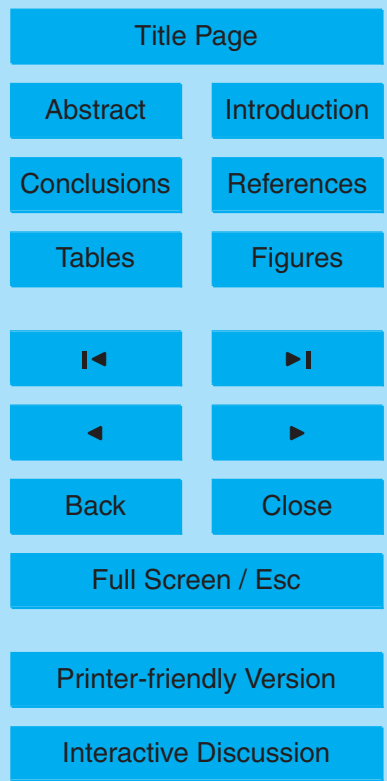


for the total aerosol flux) and hence the most representative function fits. The size range left out from the integration happens however to coincide approximately with the particles that would shrink to below $0.1 \mu \mathrm{m} D_{p}$ when heated, particles that would be lost for the sea salt flux. Considering that number fluxes could have been shifted to below 5 the lower limit of the OPC, the $18 \%$ difference between the integrated total and sea salt aerosol fluxes calculated in Sect. 3.5, could be consistent with an internally mixed aerosol of sea salt and semi-volatile aerosol (organic carbon), in that no significant number of particles are lost when corresponding size ranges are compared.

Finally, the good fit shown in Fig. 10 when shrinking the total aerosol flux a factor 3.7 10 in diameter, support that the primary marine aerosol flux we have measured consists mainly of internally mixed particles of semi-volatile organic carbon and sea salt. A smaller amount of externally mixed particles cannot be excluded. If we accept that the primary marine aerosol was internally mixed: the non-volatile fraction, sea salt, was on average approximately $\sim 2 \%$ of the volume of the original sea spray aerosol particles.

15 This may seam a small fraction, but it is enough to form the observed sea salt flux distributions at a level that, despite detailed differences, are what to be expected from the source parameterisations MÅ03, GO03 and CL06, see Figs. 3 to 6 .

\subsection{On the aerosol droplet composition and morphology}

Fatty acids and their derivates are important components of the total organic material 20 in marine aerosols (Barger and Garret, 1976), probably present as their sodium salts (Gagosian et al., 1982; Sicre et al., 1990; Seidl, 2000). The observations by Tervahattu et al. (2002) show that there are particles that consist of a core of sea salt with an organic film, which in the outmost one or two mono-layers consisted of predominantly palmitic acid, and to some extent other $\mathrm{C}_{14}-\mathrm{C}_{18}$-fatty acids and unsaturated $\mathrm{C}_{18}$ fatty 25 acids. These substances are surfactants (surface active agents), probably originating from decomposition of marine phytoplancton and enriched on the water-air interface leading to a strong enrichment in the marine aerosol $\left(5 \times 10^{4}\right.$ to $\left.9 \times 10^{4}\right)$ compared to the bulk sea water (Marty et al., 1979). The organics in marine aerosols are almost

\section{Primary marine aerosol emissions: size, sea salt and organic}

E. D. Nilsson et al.

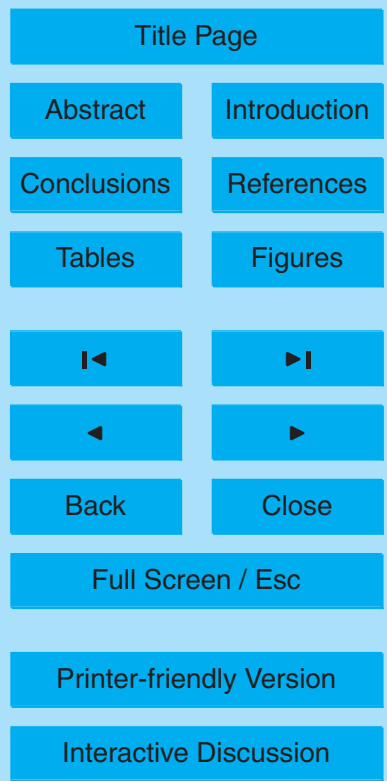

13372 
always internally mixed with sea salt, and associated with aerosol production by bubble bursting (Middlebrook et al., 1998). This agrees with our conclusions in the previous section.

Middlebrook et al. also suggests in agreement with several other studies that the or5 ganics are enriched in smaller particles compared to larger (Barker and Zeitlin, 1972; Novakov and Penner, 1993; Rivera-Carpio et al., 1996; Bezdek and Carlucci, 1974; Oppo et al., 1999). Ellison et al. (1999) presented a conceptual model for the morphology of marine aerosols where a brine of sea salt and water is encapsulated by a monolayer of hydrophobic molecules. They use stearate as a model molecule, which 10 would form a monolayer that is $2.5 \times 10^{-11} \mathrm{~m}(25 \AA)$ thick. This conceptual model results in $1 \%$ organics at $1 \mu \mathrm{m}, 5 \%$ at $200 \mathrm{~nm}$, and $50 \%$ at $10 \mathrm{~nm}$ diameters, respectively. These diameters include the water as well and the fraction is in percentage of the total mass including water. Ellison et al. (1999) argues that "sea-spray generated aerosols will shrink in size by continuously ejecting $\mathrm{H}_{2} \mathrm{O}$ molecules up to the point where a complete hydrocarbon surface mono layer encapsulates the aerosol. At this point, water evaporation ceases, and the aerosol no longer shrinks in size." Neither should this aerosol take up any water until the hydrophobic surface has been transformed by chemical reactions. The brine inside the aerosol should have a sea salt concentration somewhere in between the original ocean salinity of $\sim 3.5 \%$ and the maximum solubility of sea salt (the major component of sea salt $\mathrm{NaCl}$ has a solubility corresponding to $\sim 16.6 \%$ salinity). Which salinity and diameter the aerosol will have depends on how much organic surfactant that is available and how much the drop must shrink until the molecules form a complete monolayer. If the surface is already saturated with surface active organic molecules from the start, it may not shrink at all, and any surplus molecules may form micelles inside the droplets. It is not clear that an aerosol particle with a complex chemical composition in its surface layer with different surface active molecules will behave exactly like this, but we have to consider the possibility that surfactants and water are playing us this trick. To heat an airflow $10-20^{\circ} \mathrm{C}$ in order to drive away all water to be able to measure the dry diameter (as we did for our total aerosol

\section{Primary marine aerosol emissions: size, sea salt and organic}

E. D. Nilsson et al.

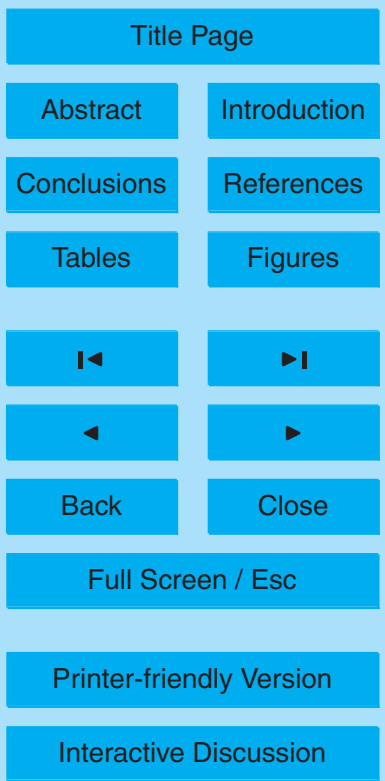


flux) is an accepted standard method, but particles built according to the Ellison et al. (1999) model will not shrink, or only partly shrink at this low heating, while both the organic surface film and the water should leave when we heat to $300^{\circ} \mathrm{C}$. This implies that the ratio between total aerosol and sea salt volume flux includes an unknown 5 fraction of water. The exact amount will depend on the original relationship between organic surfactant molecules, water and sea salt, and it will change strongly with size.

Figure 11a shows again the MÅ03 sea salt emissions at median conditions corresponding to our data set, but shifted a factor 3.7 in diameter (red curve) without changing the volume flux, thereby moving the sea salt to the size of the particles of which it

10 supposedly were a part of. To determine the amount of water to add to the MÅ03-sea salt, we have in the example of Fig. 11a given the brine solution in the sea spray the salinity of $16.6 \%$. On top of this brine aerosol we have added a complete mono layer of organic carbon, following the Ellison et al. (1999) model with the same assumptions and the same model molecule (stearate) as in Ellison et al. (1999) to represent the 15 (insoluble) organic carbon volume emission in the aerosol droplets (light green curve). The sum of the modelled sea salt, water and organic carbon volume flux (dark green curve) agrees fairly well with the observed median total aerosol volume flux (green circles) over most of the size range. Figure $11 \mathrm{~b}$ shows the percentage of calculated organic carbon and sea salt emissions from Fig. 11a relative to the total volume aerosol emissions excluding water, for a high and a low salinity, 16.6 and $3.5 \%$, respectively. One can see that the exact ratio is sensitive to the actual brine salinity. The 50:50 mixture for the high salinity case appears at about $0.2 \mu \mathrm{m}$ diameter, where the light green and red curves in Fig. 11a cross, and for the low salinity it appears at $0.9 \mu \mathrm{m}$ diameter. For the real sea spray emissions, the resulting salinity does not have to be

25 a constant with size and will depend on how much surface active organics there were available. With the calculations in Fig. 11a and $11 \mathrm{~b}$ based on the parameterisations by Mårtensson et al. (2003) and Ellison et al. (1999) we show that we can achieve a good agreement between models and the observed total aerosol volume emissions, using the high salinity.

\section{Primary marine aerosol emissions: size, sea salt and organic}

E. D. Nilsson et al.

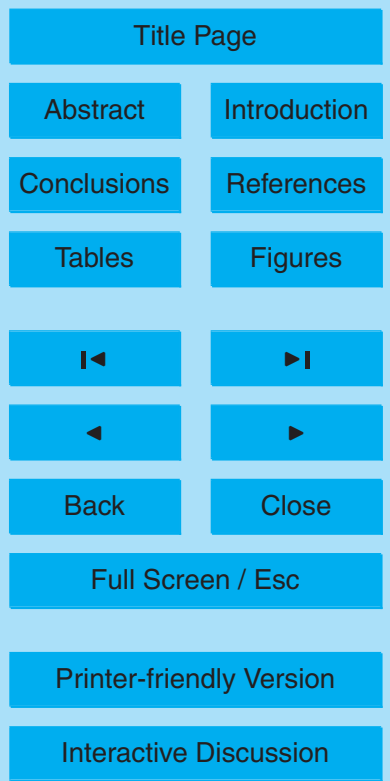

\section{4}


If we instead build on the observed volume emissions, but use the Ellison et al. (1999) model to decompose them, we can derive Fig. 11c. The observed median total aerosol volume emission flux (see Fig. 11a) can be taken apart into water (blue curves), organic carbon (green curve) and sea salt (red curves). Note that the 5 sea salt volume emission flux is now plotted at the diameter of the total aerosol. For comparison we have included the observed median sea salt aerosol emission flux (red diamonds on black curve), but shifted in size a factor 3.7 in order to place the curve at the diameter of the aerosol particles in which they were presumably included. The observed sea salt emission fluxes falls in between the two sea salt volume emission 10 curves that were calculated from the observed total volume emission and Ellison et al. (1999), based on salinities of $16.6 \%$ (full curve) and $3.5 \%$ (dashed curve), respectively. The data shown in Fig. 11c allow us to calculate the salinity of the aerosol particles to vary with size between 3.5 and $8.8 \%$ (values that would decrease if there is soluble organic carbon in the brine). This clearly show that the difference between the observed 15 sea salt and total aerosol emission fluxes can be explained if there were a mono layer of organic carbon around brine droplets, inverted micelles, as suggested by Ellision et al. (1999).

Figure 11d shows the ratios that results from replacing the sea salt aerosol volume emissions that were derived from the observed total aerosol volume emissions and 20 Ellison et al. (1999), see Fig. 11c, with the actually observed sea salt emission flux. This ratio cannot be calculated below $\sim 0.4 \mu \mathrm{m} D_{p}$ (the lower limit of the OPC shifted up in size by a factor 3.7. The calculations include a spline fit to bring both sea salt and total emissions to the same size bins. From the results in Fig. 11d, one can see how approximately $5-10 \%$ organics in the super micrometer, rapidly increase with de25 creasing diameter in the sub micrometer range towards $50 \%$ at $\sim 0.4-0.5 \mu \mathrm{m} D_{p}$. This compares in a favourable way with the chemical aerosol measurements and analysis made in Mace Head during the same summer season by Cavalli et al. (2004), see Fig. 11d. In order to mimic the conditions of the simple Ellison et al. (1999) model and use it to compare the aerosol fluxes with the impactor data, we take the sea salt

\section{Primary marine aerosol emissions: size, sea salt and organic}

E. D. Nilsson et al.

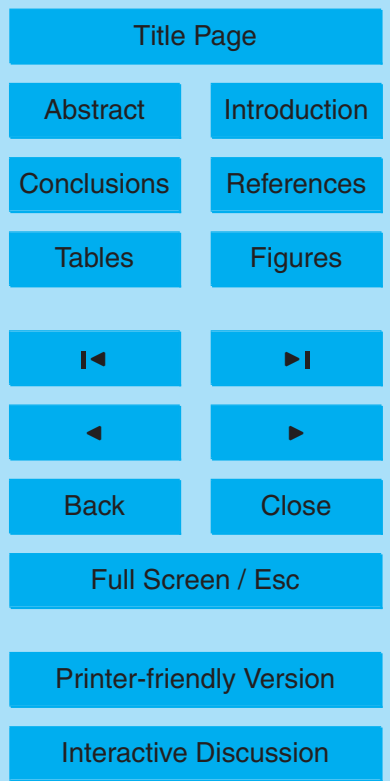

\section{5}


and the water insoluble organic carbon fractions from Fig. 2 of Cavalli et al. (2004) to represent the sea salt and the carbon aerosol surface film in the Ellison et al. (1999) model, respectively. With this we exclude all other aerosol fractions (such as non-sea salt-sulphate and ammonia) that cannot have a primary marine origin. Treated in this 5 way, their data results in just a few percents of organic carbon in the super micrometer ( 2 to $4 \%$ ) and again a rapid increase in the sub micrometer that pass $50 \%$ at $\sim 0.5 \mu \mathrm{m}$ $D_{p}$, and levels out below $0.3 \mu \mathrm{m} D_{p}$ at $80-95 \%$ organic carbon. Both the water soluble and the water insoluble fractions of Cavalli et al. (2004) show a similar behaviour. The ratio calculated from the aerosol fluxes and the Ellison et al. (1999) model catches this 10 transition rather well.

The calculations presented in Fig. 11 show that our total and sea salt aerosol emission flux observations are consistent with the Ellison et al. (1999) model, and with the size distributions of the aerosol chemistry as described by Cavalli et al. (2004). The combined MÅ03 and Ellison et al. (1999) models are able to predict the total aerosol 15 volume emissions.

Several questions remain unanswered: Organic carbon that was originally surfactants or insoluble organic carbon may have been chemically transformed into more soluble molecules as suggested by Ellison et al. (1999). Water insoluble organic carbon is not necessarily a better proxy for surfactants than the total organic carbon. For the emission fluxes (which are of a local nature) and the impactor data to agree on the organic and sea salt ratios, considering the turn over time of aerosol particles in these size ranges, and that the bulk aerosol must be the integrated result of sources and sinks and transformations upwind, the bulk aerosol must be dominated by relatively late emissions, or the local emissions must be representative for larger areas (compare with arguments in Nilsson et al., 2001). Ellison et al. (1999) estimates that the molecules in the mono layer of a primary marine aerosol particle would react with an $\mathrm{OH}$ radical within $10 \mathrm{~h}$. Altogether considered, even if the ratios of sea salt and organic carbon compares well between fluxes and bulk aerosol mass in this case, one cannot by definition expect it to do so. If we wish to compare our primary marine

\section{Primary marine aerosol emissions: size, sea salt and organic}

E. D. Nilsson et al.

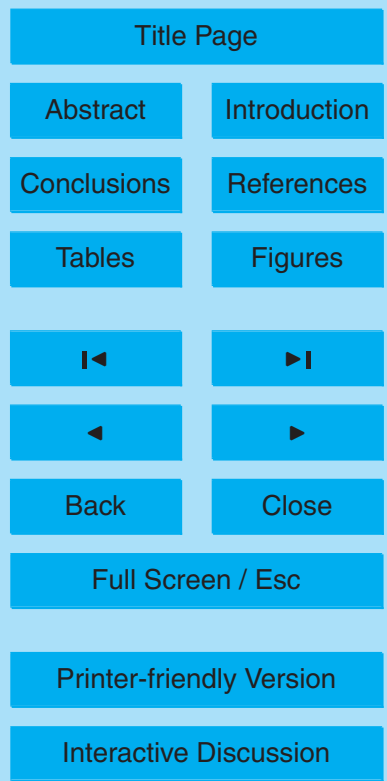


aerosol source fluxes and their ratio of volatile and non-volatile compounds to other data of guarantied local and fresh origin, we can only safely compare with other in situ flux measurements or with laboratory bubble-aerosol experiments where other aerosol sources were eliminated. Our flux measurements are the first of their kind, so there 5 are no previous data to compare to. Chemical analysis of the aerosol formed under controlled laboratory conditions can be compared with our in situ flux measurements if conducted with care: including the removal of pre-existing aerosol and thereby the influence of all other aerosol sources. Several such studies show high enrichment factors for both anthropogenic (Saint-Louis and Pelletier, 2004; Cincinelli et al., 2001) 10 and natural (Marcomini et al., 2001) organic compounds, and corresponding relative reduction of the sea salt content, in both the surface film and the resulting aerosol, compared to the bulk seawater. There is even evidence for a transition from saline to almost entirely organic particles when entering the sub micrometer size range (Oppo et al., 1999). These results follow the Ellison et al. (1999) model in that the organic fraction increases with decreasing diameter.

In one extreme, in absence of organic surfactants, no mono layer would form, and if it is dry enough in the air, pure sea salt particles would remain. This explains how field experiments such as this study and Clarke et al. (2006) can reproduce the laboratory experiments by Mårtensson et al. (2003), where artificial sea water without the organic component formed a pure sea salt size spectrum, because we in this study like Clarke et al. (2006) separated the sea salt fraction by removing the more volatile fractions. On the other hand, if there is plenty of organic carbon, what will happen with organic surfactant molecules that are left over when the monolayer is complete? Do they form micelles inside the brine? Will the droplets even be unstable and subject to fission 25 mechanisms as suggested by Donaldson et al. $(2001,2002)$ ? It is beyond the scope of this manuscript to answer these questions, but we want to make the point that these are important questions for future studies oriented towards the chemical characterisation of sea spray aerosol on the single particle level.

\section{Primary marine aerosol emissions: size, sea salt and organic}

E. D. Nilsson et al.

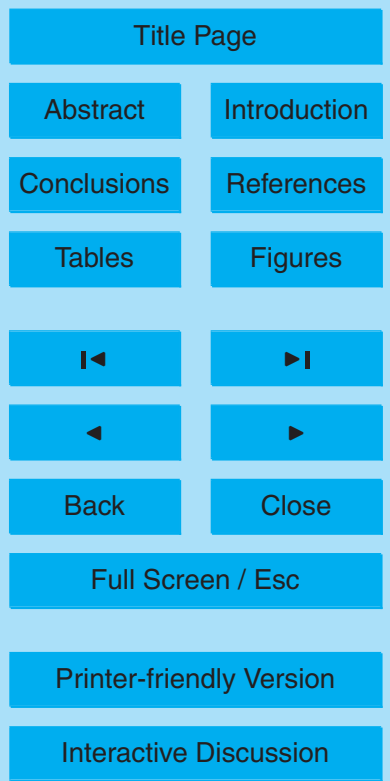




\section{Summary and conclusions}

The summarised results of this study are:

1. These are the first successful aerosol eddy covariance flux measurements over the Ocean that presents a full size resolution in the OPC range. The aerosol fluxes were dominated by an upward flux presumably aerosol production caused by bubble bursting at the ocean surface, and can be used as a proxy for emission fluxes. We have been able to characterise the size resolved aerosol number emission flux in full detail in the OPC range from $0.1 \mu \mathrm{m}$ up to 1.1 or $4 \mu \mathrm{m}$ diameter, for sea salt and total aerosol, respectively. The flux is strongly size dependent and decreases $\sim 2$ orders of magnitude from $0.1 \mu \mathrm{m}$ to the super micrometer range.

2. We have also measured the non-volatile aerosol number emission flux in the OPC range, in order to isolate the sea salt fraction of the emissions. The resulting sea salt emission size distribution agrees well with the source parameterisation by Mårtensson et al. (2003) at the corresponding water temperature $\left(12^{\circ} \mathrm{C}\right)$ in the size range 0.1 to $1.1 \mu \mathrm{m} D_{p}$, considering the median flux, the variability in the data set, and considering the flux at different wind speed conditions, often even at individual half hour periods. This implies that our results are consistent with the power law dependency on wind speed $U^{3.41}$ that originates from the white cap coverage on the form given by Monahan and O'Muircheartaigh (1980), although we cannot confirm the exact value 3.41. The power law gives a better correlation between emission fluxes and wind speed than the exponential law.

3. Among the three sub micrometer sea salt source parameterisations we have compared, the parameterisation by Mårtensson et al. (2003) shows the best agreement with the observations. While our EC emission flux data does not agree with the Clarke et al. (2006) data or parameterisation, the Clarke et al. (2006) parameterisation agrees fairly well with Mårtensson et al. (2003) when it is used for the water temperature of the Clarke et al. (2006) measurements $\left(25^{\circ} \mathrm{C}\right)$. With that,

\section{Primary marine aerosol emissions: size, sea salt and organic}

E. D. Nilsson et al.

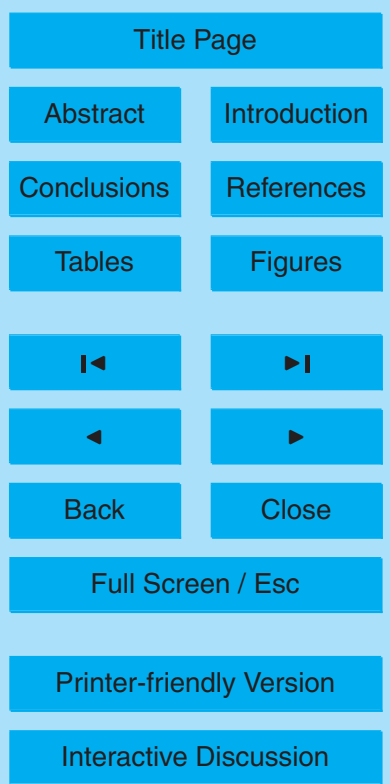


one can consider Mårtensson et al. (2003) to be validated both for temperate and tropical temperatures.

4. The total aerosol emissions are larger than the sea salt emission by a ratio that appears to be dependent on the wind speed. The sea salt emission fluxes increase with increasing wind speed throughout the observation range $\left(\sim 4\right.$ to $\left.22 \mathrm{~ms}^{-1}\right)$. On the contrary, at wind speeds up to $10 \mathrm{~ms}^{-1}$, the total flux had no significant wind speed dependency, staying at a high level throughout the wind range. Above $10 \mathrm{~ms}^{-1}$ wind speed the total emissions increased with the wind speed, while the sea salt number emissions approach the total emissions at $15 \mathrm{~ms}^{-1}$. We speculate that this may be due to the gradual depletion of the organic film and colloid particles in the surface water. We suspect that the organic carbon fraction depends strongly on biological activity and changes from site to site and over the seasons. The current result may be in the upper range due to high biological production.

5. The results are most consistent with an internal mixture of sea salt, organic carbon and water. Evidences are: similar integrated magnitude of the relevant size ranges of the total and sea salt number emission fluxes, similar slope and fit properties between the wind speed and the total and sea salt emissions respectively, and a good agreement between the total and sea salt volume emission when shifted a factor $\sim 3.7$ in diameter size. This is in agreement with previous studies that rarely found marine organic aerosol particles without sea salt (e.g. Middlebrook et al., 1998).

6. The simple morphological aerosol model by Ellison et al. (1999) can be used to show that our observed total and sea salt aerosol emission fluxes are consistent with each other. We have also shown that the combination of the Mårtensson et al. (2003) sea salt emission model and the model by Ellison et al. (1999) roughly can be used to predict the observed total aerosol emission flux. This implies that the sea salt predicted by Mårtensson et al. (2003) forms concentrated brine 13379

\section{Primary marine aerosol emissions: size, sea salt and organic}

E. D. Nilsson et al.

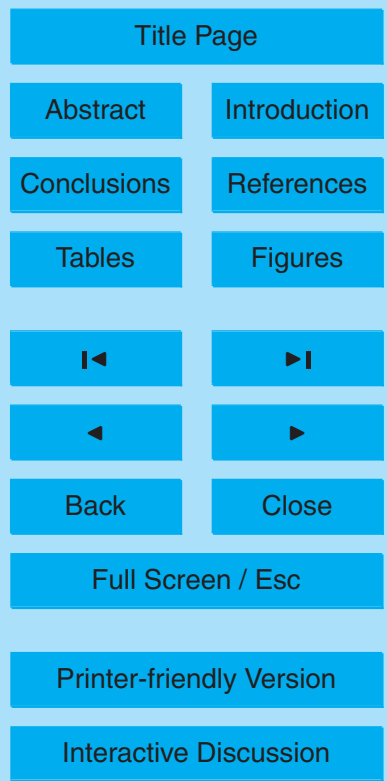


droplets surrounded by a mono layer of organic surfactant molecules, and gives an estimate of the distribution of water and organic carbon at different sizes. Similar calculations utilising the Ellison et al. (1999) model plus both the observed total and sea salt emission fluxes predict that the salinity in the droplets was between 3.5 and $8.8 \%$. It also predicts a size distribution of the ratio of organic carbon and the total of sea salt and organic carbon of a few \% above $1 \mu \mathrm{m} D_{p}$ and approaching $50 \%$ at $\sim 0.5 \mu \mathrm{m} D_{p}$, which is in excellent agreement with the observations of the aerosol chemistry mass size distribution at Mace Head during the same summer that was reported by Cavalli et al. (2004). The introduction of the Ellison et al. (1999) model in the data analysis, either directly to the data or through the Mårtensson et al. (2003) parameterisation is able to give a consistent explanation to the aerosol chemical data as well as our total and sea salt emissions. It also probably offers the best possibility so far to parameterise the organic fraction of the primary marine aerosol source.

15 We have shown that eddy covariance is a powerful tool when estimating the primary marine aerosol emissions, and that the results can be compared with well-designed laboratory experiments. Although there is now a first validation of Mårtensson et al. (2003) and Clarke et al. (2006) can be seen as another validation, it is obvious that more measurements at various conditions and seasons over different oceans and wind speeds are needed. Highest priority should be give to quantification and characterisation of the sub-100-nm range and the organic fraction. The tools for this is probably to combine

1. The currently presented method, which combines the EC method with CPC and OPC measurements at different volatility.

2. The relaxed eddy accumulation (REA) method, which allow us to calculate fluxes from slow sensors/systems, such as differential mobility particle sizing systems (DMPS) for size resolved fluxes below the OPC range, again at different volatility.

\section{Primary marine aerosol emissions: size, sea salt and organic}

E. D. Nilsson et al.

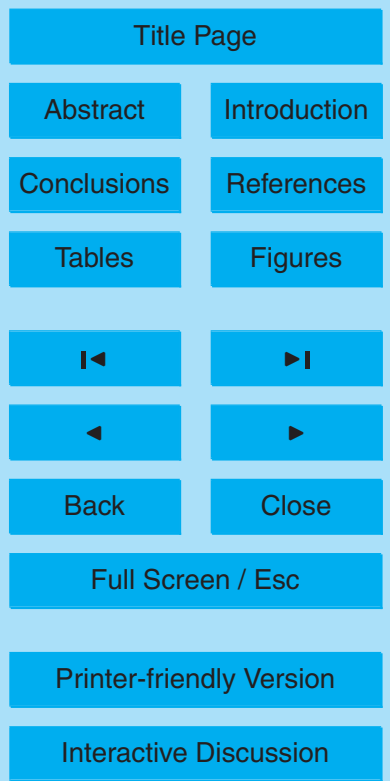

\section{0}


3. To combine such in situ flux measurements with in situ tank experiments using on line in situ water samples.

Important problems remains to be solved regarding the morphology of the primary marine aerosol, not only connected to the formation processes and the parameterisation of the organic fraction in the sea spray, but also necessary to understand how this aerosol interact with atmospheric chemistry, other aerosol particles, solar radiation and with water and clouds. A final warning must be issued to modellers. Although there is now a sub micrometer sea salt source parameterisation that is validated in a wide size range for both temporal and tropical water, applying this parameterisation in a model without considering the organic fraction and the particle morphology may place the sea salt in the wrong size bins of the model, where it would be exposed to the wrong deposition, coagulation, condensation and cloud activation, and where it would create aerosol particles with very different properties as cloud condensation nucleus.

Acknowledgements. The Swedish Research Council is acknowledged for several research in particularly. The QUEST and MAP-projects was supported by the European Commission. We are obliged to the people who helped keeping the flux system running in Mace Head over the summer of 2002. We would also wish to thank M. C. Facchini and F. Cavalli for their assistance when supplying us with the aerosol impactor data shown in Fig. 11.

\section{References}

Adams, P. J. and Seinfeld, J. H.: Disproportionate impact of particulate emissions on global cloud condensation nuclei concentrations, Geophys. Res. Lett., 30(5), 1239, doi:10.1029/2002GL016303, 2003.

Albrecht, B.: Aerosols, cloud microphysics and fractional cloudiness. Science, 245, 1227-1230, 1989

Anastasio, C. and Newberg, J. T.: Sources and sinks of hydroxyl radical in sea-salt particles, J. Geophys. Res., 112, D10306, doi:10.1029/2006JD008061, 2007.

\section{Primary marine aerosol emissions: size, sea salt and organic}

E. D. Nilsson et al.

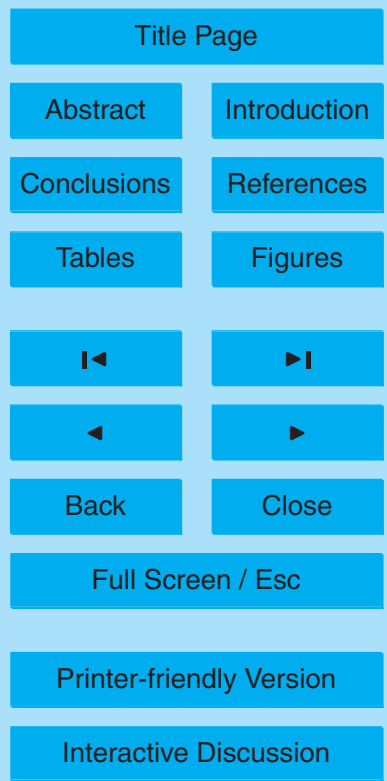


Barger, W. R. and Garret, W. D.: Surface-active organic material in air over the Mediterranean and over eatern equatorial Pacific, J. Geophys. Res., 81, 3151-3157, 1976.

Barker, D. R. and Zeitlin, H.: Metal-ion concentrations in sea-surface microlayer and sizeseparated atmospheric aerosol samples in Hawaii, J. Geophys. Res., 77, 5076-5088, 1972.

5 Bezdek, H. F. and Carlucci, A. F.: Concentrations and removal of liquid microlayers from a seawater surface by bursting bubbles, Limnol. Oceanogr., 19, 126-134, 1974.

Boucher, O. and Lohmann, U.: The sulfate-CCN-cloud albedo effect - a sensitivity study with 2 general-circulation models, Tellus B, 47, 281-300, 1995.

Bowyer, P. A., Woolf, D. K., and Monahan, E. C.: Temperature dependence of the charge and aerosol production associated with a breaking wave in a whitecap simulation tank, J. Geophys. Res., 95, 5313-5319, 1990.

Brooks, B. J., Smith, M. H., Hilla, M. K., and O'Dowd, C. D.: Size-differentiated volatility analysis of internally mixed laboratory-generated aerosol, Aerosol Sci., 33, 555-579, 2002.

Buzorius, G., Rannik, Ü., Nilsson, E. D., Vesala, T., and Kulmala, M.: Analysis of dry deposition velocity measurement techniques for particles smaller than $100 \mathrm{~nm}$, J. Aerosol Sci., 34, 747764, 2003.

Caffrey, P. F., Hoppel, W. A., and Shi, J. J.: A one-dimensional sectional aerosol model integrated with mesoscale meteorological data to study marine boundary layer aerosol dynamics, J. Geophys. Res., 111, D24201, doi:10.1029/2006JD007237, 2006.

Cavalli, F., Facchini, M. C., Decesari, S., Mircea, M., Emblicia, L., Fuzzi, S., Ceburnis, D., Yoon, Y. J., O'Dowd, C. D., Putaud, J.-P., and Dell'Acqua, A.: Advances in characterization of sizeresolved organic matter in marine aerosol over the North Atlantic, J. Geophys. Res., 109, D24215, doi:10.1029/2004JD005137, 2004.

Chameides, W. L. and Stelson, A. W.: Aqueous-phase chemical processes in deliquescent sea-salt aerosols - A mechanism that couples the atmospheric cycles of $\mathrm{S}$ and sea salt, $\mathrm{J}$. Geophys. Res., 91(D18), 20565-20580, 1992.

Cipriano, R. J., Monahan, E. C., Bowyer, P. A., and Woolf, D. K.: Marine condensation nucleus generation inferred from whitecap simulation tank results, J. Geophys Res., 92, 6569-6576, 1987.

30 Cincinelli, A., Stortini, A. M., Perugini, M., Chacchini, L., and Lepri, L.: Organic pollutants in sea-surface microlayer and aerosol in the coastal environment of Leghorn - (Tyrrhenian Sea), Marince Chem., 76, 77-98, 2001.

Clarke, A. D., Owens, S. R., and Zhou, J.: An ultrafine sea-salt flux from breaking waves:

\section{Primary marine aerosol emissions: size, sea salt and organic}

E. D. Nilsson et al.

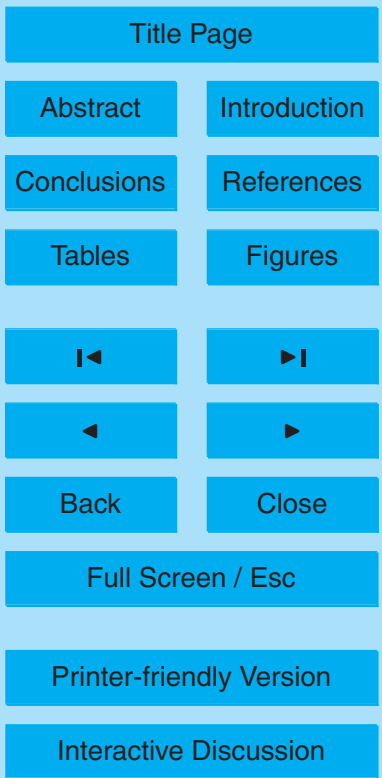


Implications for cloud condensation nuclei in the remote marine atmosphere, J. Geophys Res., 111, D06202, doi:10.1029/2005JD006565, 2006.

de Leeuw, G., Kunz, G. J., Buzorius, G., and O'Dowd, C. D.: Meteorological influences on coastal new particle formation, J. Geophys. Res., 107(D19), 8102, doi:10.1029/2001JD001478, 2002.

Donaldson, D. J. and Anderson, D.: Adsorption of Atmospheric Gases at the Air-Water Interface. 2. C1-C4 Alcohols, Acids and Acetone, J. Phys. Chem., A 103, 871-876, 1999.

Donaldson, D. J., Tuck, A. F., and Vaida, V.: Spontaneous fission of atmospheric aerosol particles, Phys. Chem. Chem. Phys., 3, 5270-5273, 2001.

10 Donaldson, D. J., Tuck, A. F., and Vaida, V.: The asymmetry of organic aerosol fission and prebiotic chemistry, Orig. Life Evol. Biosph., 32, 237-245, 2002.

Donaldson, D. J., Tervahattu, H., Tuck, A. F., and Vaida, V.: Organic aerosols and the origin of life , Orig. Life Evol. Biosph., 34, 57-67, 2004.

Ellison, G. B., Tuck, A. F., and Vaida, V.: Atmospheric processing of organic aerosols, J. Geophys. Res., 104, 11633-11641, 1999.

Finlayson-Pitt, B. J. and Pitts Jr., J. N..: Tropospheric air pollution: ozone, airborne toxics, polycyclic aromatic hydrocarbons, and particles, Science, 276, 1045-1052, 1997.

Foltescu, V. L., Pryor, S. C., and Bennet, C.: Sea salt generation, dispersion and removal on the regional scale, Atmos. Environ. 39, 2123-2133, 2005.

20 Gagosian, R. B., Zafiriou, O. C., Peltzer, E. T., and Alford, J. B.: Lipids in aerosols from the tropical North Pacifics - temporal variability, J. Geophys. Res., 87 (NC13), 1133-1144, 1982.

Geever, M., O'Dowd, C. D., van Ekeren, S., Flanagan, R., Nilsson, E. D., de Leeuw, G. and Rannik, Û.: Sub-micron sea-spray fluxes, Geophys. Res. Lett., 32, L15810, 2005.

Glantz, P., Svensson, G., Noone, K. J., and Osborne, S. R.: Sea-salt aerosols over the northeast Atlantic: Model simulations of the ACE-2 Second Lagrangian experiment, Q. J. R. Meteorol. Soc., 130, 2191-2215, 2004.

Gong, S. L., Barrie, L. A., and Blanchet, J.-P.: Modeling sea-salt aerosols in the atmosphere 1. Model development, J. Geophys. Res., 102, 3805-3818, 1997.

Gong, S. L., Barrie, L. A., and Lazare, M.: Canadian Aerosol Module (CAM): A size-segregated simulation of atmospheric aerosol processes for climate and air quality models, 2, Global sea-salt aerosol and its budgets, J. Geophys. Res., 107, 4779, doi:10.1029/2001JD002004, 2002.

Gong, S. L.: A parameterization of sea-salt aerosol source function for sub- and super-micron

\section{Primary marine aerosol emissions: size, sea salt and organic}

E. D. Nilsson et al.

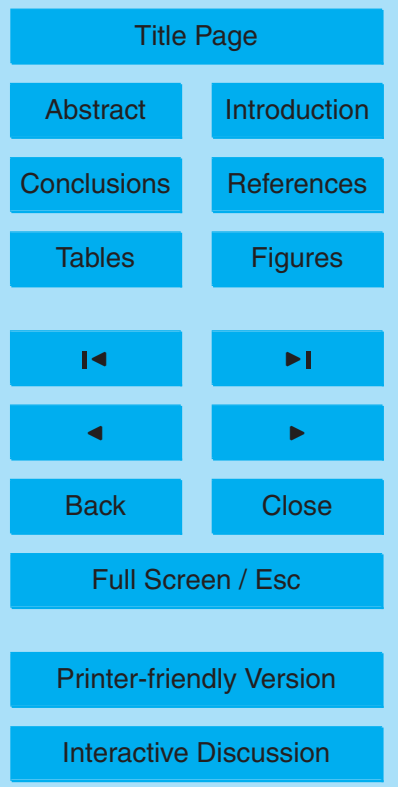


particles, Global Biogeochem. Cycles, 17(4), 1097, doi:10.1029/2003GB002079, 2003.

Grini, A., Myhre, G., Sundet, J. K., and Isaksen, I. S. A.: Modeling the Annual Cycle of Sea Salt in the Global 3D Model Oslo CTM2: Concentrations, Fluxes, and Radiative Impact, J. Climate 15, 1717-1730, 2002.

5 Guelle, W., Schulz, M., Balkanski, Y., and Dentener, F.: Influence of the source formulation on modeling the atmospheric global distribution of sea salt aerosol, J. Geophys. Res., 106, $27509-27524,2001$.

Heard, D.E., Read, K. A., Methven, J., Al-Haider, S., Bloss, W. J., Johnson, G. P., Pilling, M. J., Seakins, P. W., Smith, S. C., Sommariva, R., Stanton, J. C., Still, T. J., Brooks, B., de Leeuw, G., Jackson, A. V., McQuaid, J. B., Morgan, R., Smith, M. H., Carpenter, L. J., Carslaw, N., Hamilton, J., Hopkins, J. R, Lee, J. D., Lewis, A. C., Purvis, R. M., Wevill, D. J., Brough, N., Green, T., Mills, G., Penkett, S. A., Plane, J. M. C., Saiz-Lopez, A., Worton, D., Monks, P. S., Fleming, Z., Rickard, A. R., Alfarra, M., Allan, J. D., Bower, K., Coe, H., Cubison, M., Flynn, M., McFiggans, G., Gallagher, M., Norton, E. G., O'Dowd, C. D., Shillito, J., Topping, 15 D., Vaughan, G., Williams, P., Bitter, M., Ball, S. M., Jones, R. L., Povey, I. M., O'Doherty, S., Simmonds, P. G., Allen, A., Kinnersley, R. P., Beddows, D. C. S., Dall'Osto, M., Harrison, R. M., Donovan, R. J., Heal, M. R., Jennings, S. G., Noone, C., and Spain, G.: The North Atlantic Marine Boundary Layer Experiment (NAMBLEX). Overview of the campaign held at Mace Head, Ireland, in summer 2002, Atmos. Chem. Phys., 6, 2241-2272, 2006.

IPCC, 2001: Climate change: The scientific basis, edited by: Houghton, J. T., Ding, Y., Griggs, D. J., Noguer, M., van der Linden, P. J., and Xiaosu, D., Cambridge University Press, Cambridge, UK, 2001.

Keene, W. C., Maring, H., Maben, J. R., Kieber, D. J., Pszenny, A. A. P., Dahl, E. E., Izaguirre, M. A., Davis, A. J., Long, M. S., Zhou, X., Smoydzin, L., and Sander, R.: Chemical and Physical Characteristics of Nascent Aerosols Produced by Bursting Bubbles at a Model AirSea Interface, J. Geophys. Res., in press, 2007.

Kiehl, J. T. and Briegleb, B. P.: The relative roles of sulfate aerosols and greenhouse gases in climate forcing, Science, 260, 311-314, 1993.

Koch, D., Schmidt, G. A., and Field, C. V.: Sulfur, sea salt, and radionuclide aerosols in GISS ModelE, J. Geophys. Res., 111, D06206, doi:10.1029/2004JD005550, 2006.

Kunz, G. J. and de Leeuw, G.: Micrometeorological characterisation of the Mace Head field station during PARFORCE, in: New particle formation and fate in the coastal environment (PARFORCE), edited by: O'Dowd, C. and Hämeri, K., Report Series in Aerosol Science, 48,

\section{Primary marine aerosol emissions: size, sea salt and organic}

E. D. Nilsson et al.

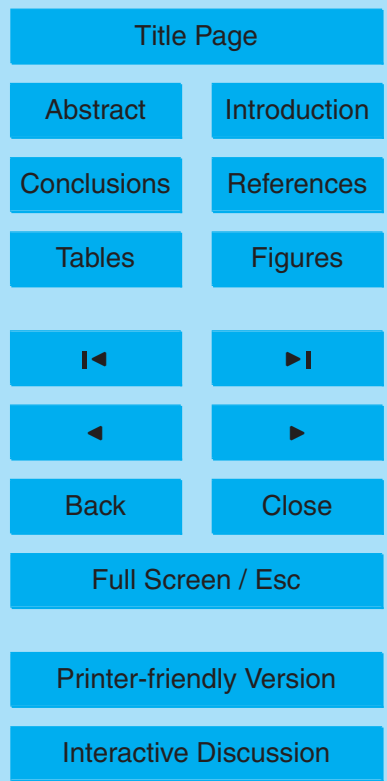


2000, ISBN 952-5027-23-6., 55-62, 2000.

Latham, J. and Smith, M. H.: Effect on global warming of wind-dependent aerosol generation at the ocean surface, Nature, 347, 372-373, 1990.

Marcomini, A., Pojana, G., Giacometti, A., and Oppo, C.: Aerosolization of an anionic surfactant 5 (LAS) and dissolved organic carbon (DOC) under laboratory conditions, Chemosphere, 44, 257-262, 2001.

Marty, J. C., Saliot, A., Buatmenard, P., Chesselet, R., and Hunter, K. A.: Relationship between the lipid composition of marine aerosols, the sea-surface micro-layer and the subsurface water, J. Geophys. Res., 84 (NC9), 5707-5716, 1979.

10 Matsumoto, K., Nagao, I., Tanaka, H., Miyaji, H., lida, T., and Ikebe, Y.: Seasonal characteristics of organic and inorganic species and their size distributions in atmospheric aerosols over the northwest Pacific Ocean, Atmos. Environ., 32, 1931-1946, 1998.

Middlebrook, A., M., Murphy, D. M., and Thomson, D. S.: Observations of organic material in individial marine particles at Cape Grim during the First Aerosol Characterisation Experiment

15 (ACE 1), J. Geophys. Res., 103, 16 475-16 483, 1998.

Monahan, E. C. and O'Muircheartaigh, I.: Optimal power-law description of oceanic whitecap coverage dependence on wind speed, J. Phys. Oceanogr., 10, 2094-2099, 1980.

Monahan, E. C. and Davidson, K. L.: Whitecap Aerosol productivity Deduced from Simulation Tank Experiments, J. Geophys. Res., 87, 8898-8904, 1982.

20 Monahan, E. C., Spiel, D. E., and Davidson, K. L.: A model of marine aerosol generation via whitecaps and wave disruption, in Oceanic whitecaps, edited by: Monahan, E. C. and MacNiochaill, G., 167-193, D. Reidel Publ. Comp., 1986

Murphy, D. M., Anderson, J. R. , Quinn, P. K., McInnes, L. M., Brechtelk, F. J., Kreidenweisk,, S. M., Middlebrook, A. M., Pósfai, M., Thomson, D. S., and Buseck, P. R.: Influence of sea-salt on aerosol radiative properties in the Southern Ocean marine boundary layer, Nature, 392, 62-65, 1998.

Mårtensson, E.M., Nilsson, E. D., de Leeuw, G., Cohen, L. H., and Hansson, H.-C.: Laboratory simulations and parameterization of the primary marine aerosol production, J. Geophys. Res., 108, 4297, doi:10.1029/2002JD002263, 2003.

30 Nilsson, E. D., Rannik, Ü., Swietlicki, E., Leck, C., Aalto, P. P., Zhou, J., and Norman, M.: Turbulent aerosol fluxes over the Arctic Ocean 2. Wind-driven sources from the sea, J. Geophys. Res., 106, 32 111-32 124, 2001.

Norton, E. G., Vaughan, G., Methven, J., Coe, H., Brooks, B., Gallagher, M., and Longley, I.:

\section{Primary marine aerosol emissions: size, sea salt and organic}

E. D. Nilsson et al.

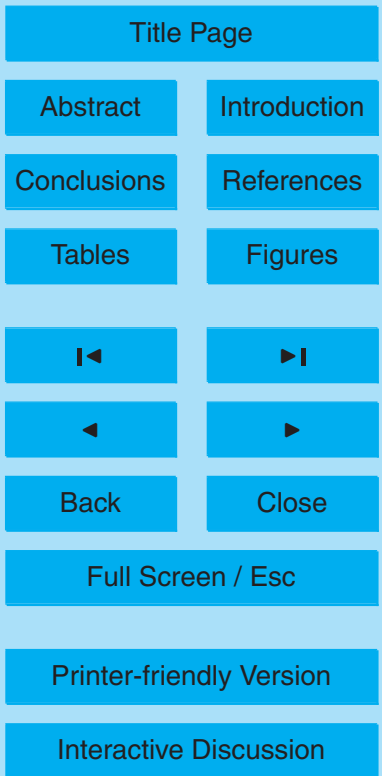


Boundary layer structure and decoupling from synoptic scale flow during NAMBLEX, Atmos. Chem. Phys., 6, 433-445, 2006,

http://www.atmos-chem-phys.net/6/433/2006/.

Novakov, T. and Penner, J. E.: Large contribution of organic aerosols to cloud condensation nuclei concentrations, Nature, 265, 823-826, 1993.

Novakov, T., Corrigan, C. E., Penner, J. E., Chuang, C. C., Rosario, O., and Mayel Bracero, O. L.: Organic aerosols in the Caribbean trade winds: A natural source?, J. Geophys. Res., 102, 21307-23313, 1997.

O'Dowd, C. D. and Smith, M. H.: Physiochemical properties of aerosols over the Northeast Atlantic: evidence for wind-related submicron sea-salt aerosol production, J. Geophys. Res., 98, 1137-1149, 1993.

O'Dowd, C. D. and Smith, M. H.: Physiochemical properties of aerosols over the Northeast Atlantic: evidence for wind-related submicron sea-salt aerosol production, J. Geophys. Res., 98, 1137-1149, 1993.

O'Dowd, C. D., Lowe, J. A., and Smith, M. H.: Coupling sea-salt and sulphate interactions and its impact on cloud droplet concentration predictions, Geophys. Res. Lett., 26, 1311-1314, 1999.

O’Dowd, C. D., Facchini, M. C., Cavalli, F., Ceburnis, D., Mircea, M., Decesari, S., Fuzzi, S., Yoon, Y. J., and Putaud, J. P.: Biogenically driven organic contribution to marine aerosol, 20 Nature, 431, 676-680, 2004.

Oppo, C., Bellandi, S., Degli Innocenti, N., Stortini, A. M., Loglio, G., Schiavuta, E., and Cini, R.: Surfactant components of marine organic matter as agents for biogeochemical fracionation and pollutant transport via marine aerosols, Marine Chem., 63, 235-253, 1999.

Pierce, J. R. and Adams, P. J.: Global evaluation of CCN formation by direct emission of sea salt and growth of ultrafine sea salt, J. Geophys. Res., 111, D06203, doi:10.1029/2005JD006186, 2006.

Rivera-Carpio, C. A., Corrigan, C. E., Novakov, T., Penner, J. E., Rogers, C. F., and Chow, J. C.: Derivation of contributions of sulfate and carboneceous aerosols to cloud condensation nuclei from mass size distributions, J. Geophys. Res., 101, 19 483-19 493, 1996.

30 Saint-Loui, R. and Pellerier, E.: Sea-to-air flux of contaminants via bubbles bursting. An experimental approach for tributyltin, Marine Chem., 84, 211-224, 2004.

Seidl, W.: Model for surface film of fatty acids on rain water and aerosol particles, Atmos. Environ., 34(28), 4917-4932, 2000.

\section{Primary marine aerosol emissions: size, sea salt and organic}

E. D. Nilsson et al.

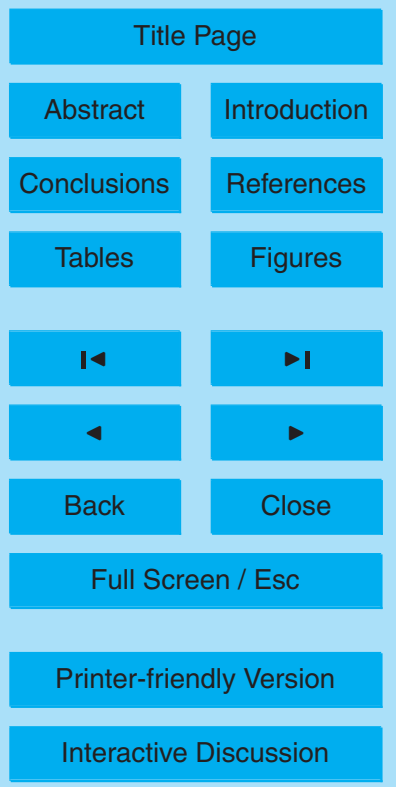


Sicre, M. A., Marty, J. C., and Saliot, A.: N-alkanes, fatty-acid esters, and fatty-acid salts in size fractionated aerosols collected over the Mediterranean Sea, J. Geophys. Res., 95, 36493657, 1990.

Spillane, M. C., Monahan, E. C., Bowyer, P. A., Doyle, D. M., and Stabeno, P. J.: Whitecaps and global fluxes, in Oceanic whitecaps, edited by: Monahan, E. C. and MacNiochaill, G., pp. 167-193, D. Reidel Publ. Comp., 1986.

Spracklen, D. V., Pringle, K. J., Carslaw, K. S., Chipperfield, M. P., and Mann, G.W.: A global off-line model of size-resolved aerosol microphysics: II. Identification of key uncertainties, Atmos. Chem. Phys., 5, 3233-3250, 2005,

10 http://www.atmos-chem-phys.net/5/3233/2005/.

Tervahattu, H., Juhanoja, J., and Kupiainen, K.: Identification of an organic coating on marine aerosol particles by TOF-SIMS, J. Geophys. Res., 107, 4319, doi:10.1029/2001JD001403, 2002.

Vignati, E., de Leeuw, G., and Berkowicz, R.: Modeling coastal aerosol transport and effects of surf-produced aerosols on processes in the marine atmospheric boundary layer, J. Geophys. Res., 106(D17), 20225-20 238, 2001.

\section{ACPD}

7, 13345-13400, 2007

\section{Primary marine aerosol emissions: \\ size, sea salt and organic}

E. D. Nilsson et al.

\section{Title Page}

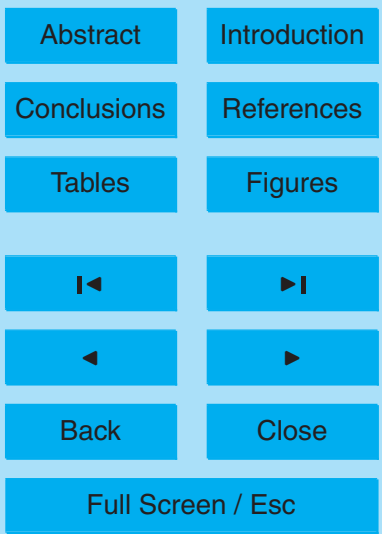

Printer-friendly Version

Interactive Discussion 


\section{ACPD}

\section{Primary marine aerosol emissions: \\ size, sea salt and \\ organic}

E. D. Nilsson et al.
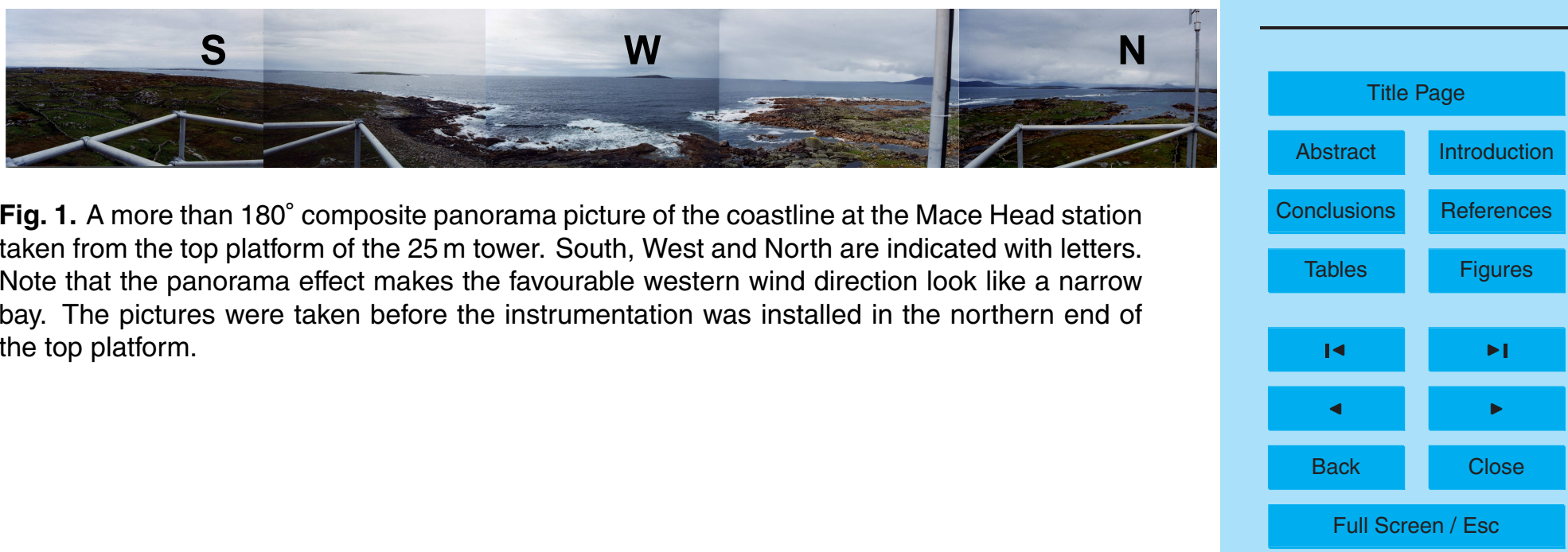

Fig. 1. A more than $180^{\circ}$ composite panorama picture of the coastline at the Mace Head station taken from the top platform of the $25 \mathrm{~m}$ tower. South, West and North are indicated with letters. Note that the panorama effect makes the favourable western wind direction look like a narrow bay. The pictures were taken before the instrumentation was installed in the northern end of the top platform.

Printer-friendly Version

Interactive Discussion 

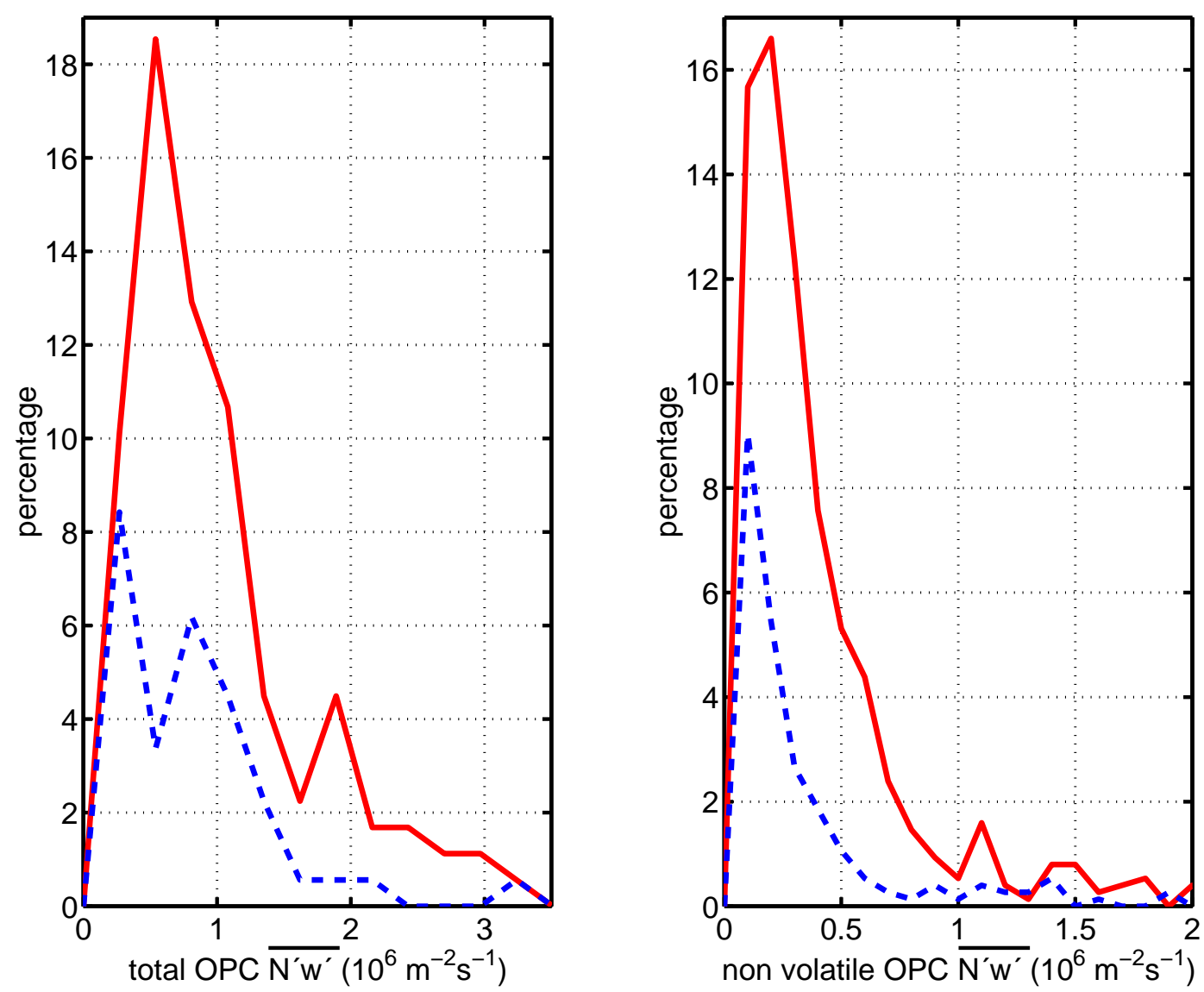

\section{ACPD}

\section{Primary marine aerosol emissions: size, sea salt and organic}

E. D. Nilsson et al.

\section{Title Page}

\section{Abstract}

Conclusions

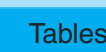

14

4

Back

Fig. 2. (a) Frequency distributions of the frequency of occurrence of different magnitudes of upward (full red curve) and downward (dashed black curve) total aerosol number flux. Only the magnitude is considered, that is the minus sign is removed from the downward fluxes. (b) Same as Fig. 2a, but for the sea salt aerosol. 


\section{ACPD}

\section{7, 13345-13400, 2007}
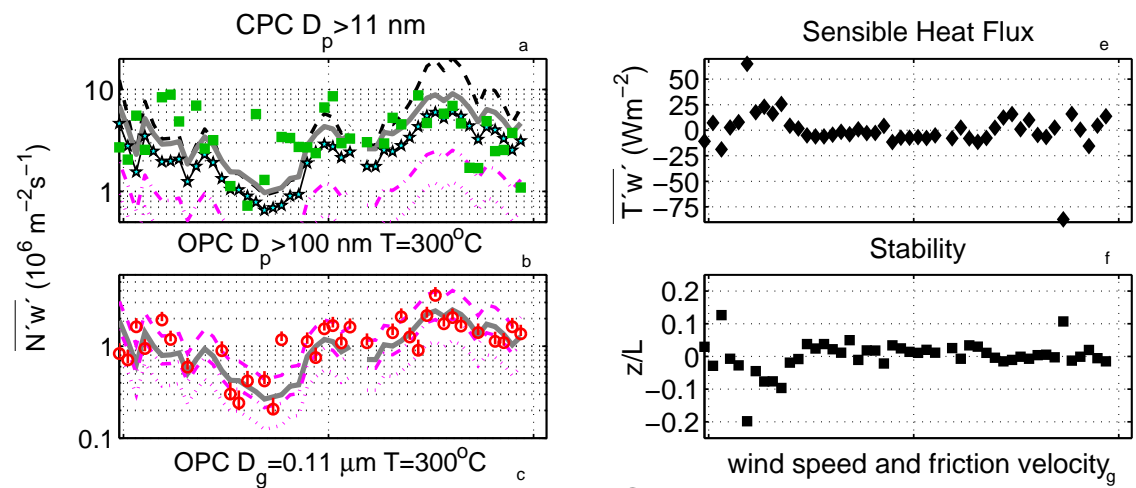

\section{Primary marine aerosol emissions: size, sea salt and organic}

E. D. Nilsson et al.
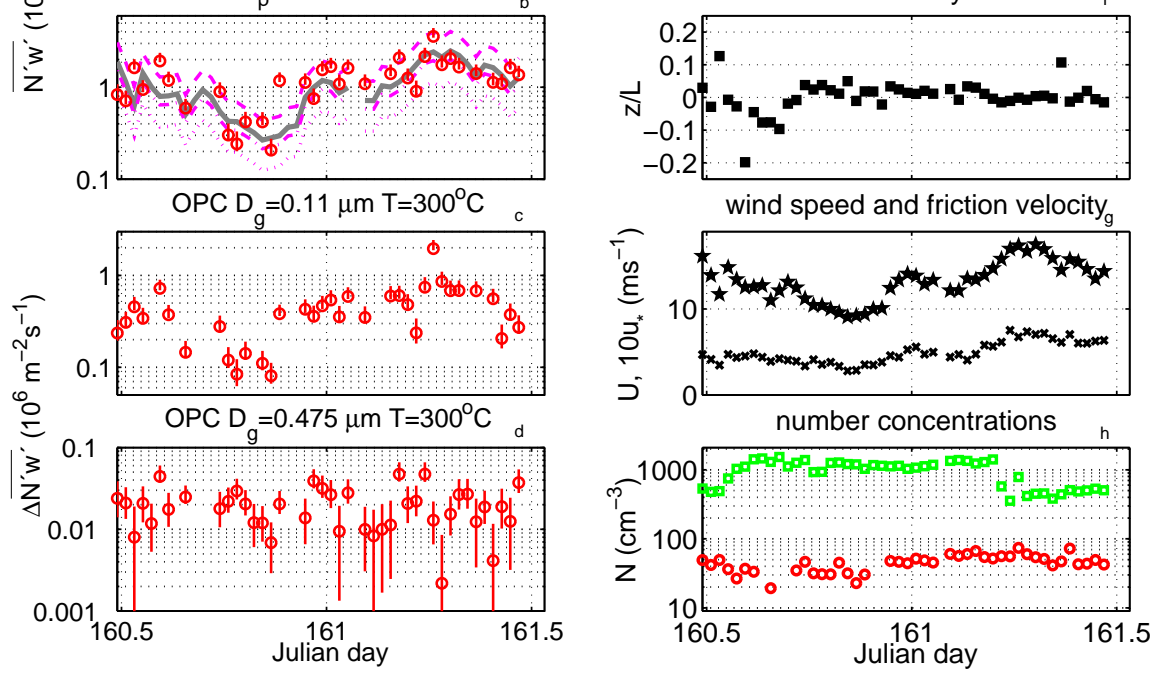

Title Page

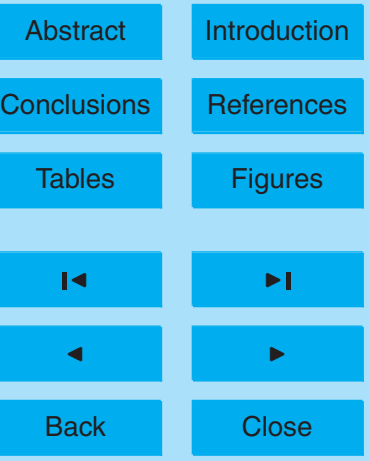

Full Screen / Esc

Fig. 3.

Printer-friendly Version

Interactive Discussion 
Fig. 3. Measurements at Mace Head 9-10 June 2002 (Julian day 160-161). (a) Total aerosol number flux for particles $>11 \mathrm{~nm} D_{p}$ (green squares). Parameterised flux according to Nilsson et al. (2001) (black dashed curve); Mårtensson et al. (2003) (grey full curve); Clark et al. (2003) (black five-point-stars with cyan centre), and Gong (2003) with $\Theta=22$ (dashed pink curve) and 44 (dotted pink curve). Gong (2003) with $\Theta=11$ is not shown since it fall almost exactly on top of Mårtensson et al. (2003). (b) Aerosol number emission flux integrated for particles $>100 \mathrm{~nm} \mathrm{D}$ at $300^{\circ} \mathrm{C}$ (red circle) with discrete counting error bars. Parameterised emissions according to Mårtensson et al. (2003) (grey full curve), integrated over $D_{p}>100 \mathrm{~nm}$; Gong (2003) with $\Theta=11$ (dashed-dotted pink curve), 22 (dashed pink curve) and 44 (dotted pink curve). Clarke et al. (2006) are not shown since it falls almost exactly on top of Mårtensson et al. (2003). (c) Aerosol number flux in the OPC size bin 100 to $120 \mathrm{~nm} D_{p}$ at $300^{\circ} \mathrm{C}$ (red circles) with discrete counting error bars. (d) Aerosol number flux in the OPC size bin 0.6 to $0.7 \mu \mathrm{m} D_{p}$ at $300^{\circ} \mathrm{C}$ (red circles) with discrete counting error bars. (e) Turbulent sensible heat flux (black diamonds). (f) Stability $z / L$ (black squares). (g) Mean horizontal wind speed at $25.5 \mathrm{~m}$ height (black pentagrams) and friction velocity (black crosses). (h) Mean aerosol number concentration for $D_{p}>11 \mathrm{~nm}$, the CPC (green squares), for $D_{p}>100 \mathrm{~nm}$, the OPC at $300^{\circ} \mathrm{C}$ (red circles).

\section{Primary marine aerosol emissions: size, sea salt and organic}

E. D. Nilsson et al.

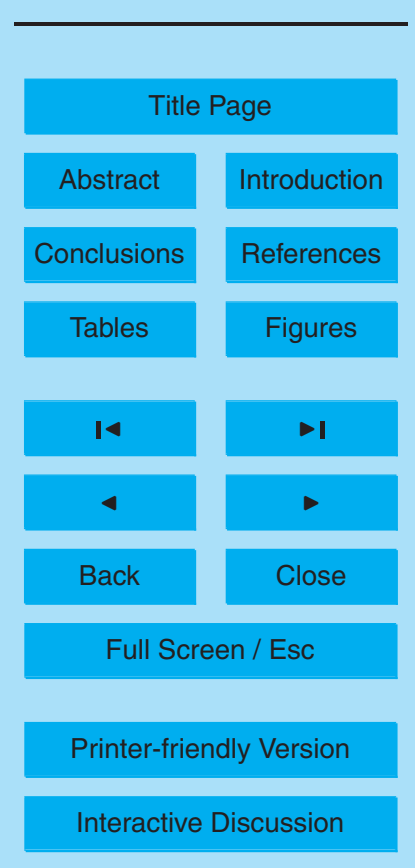



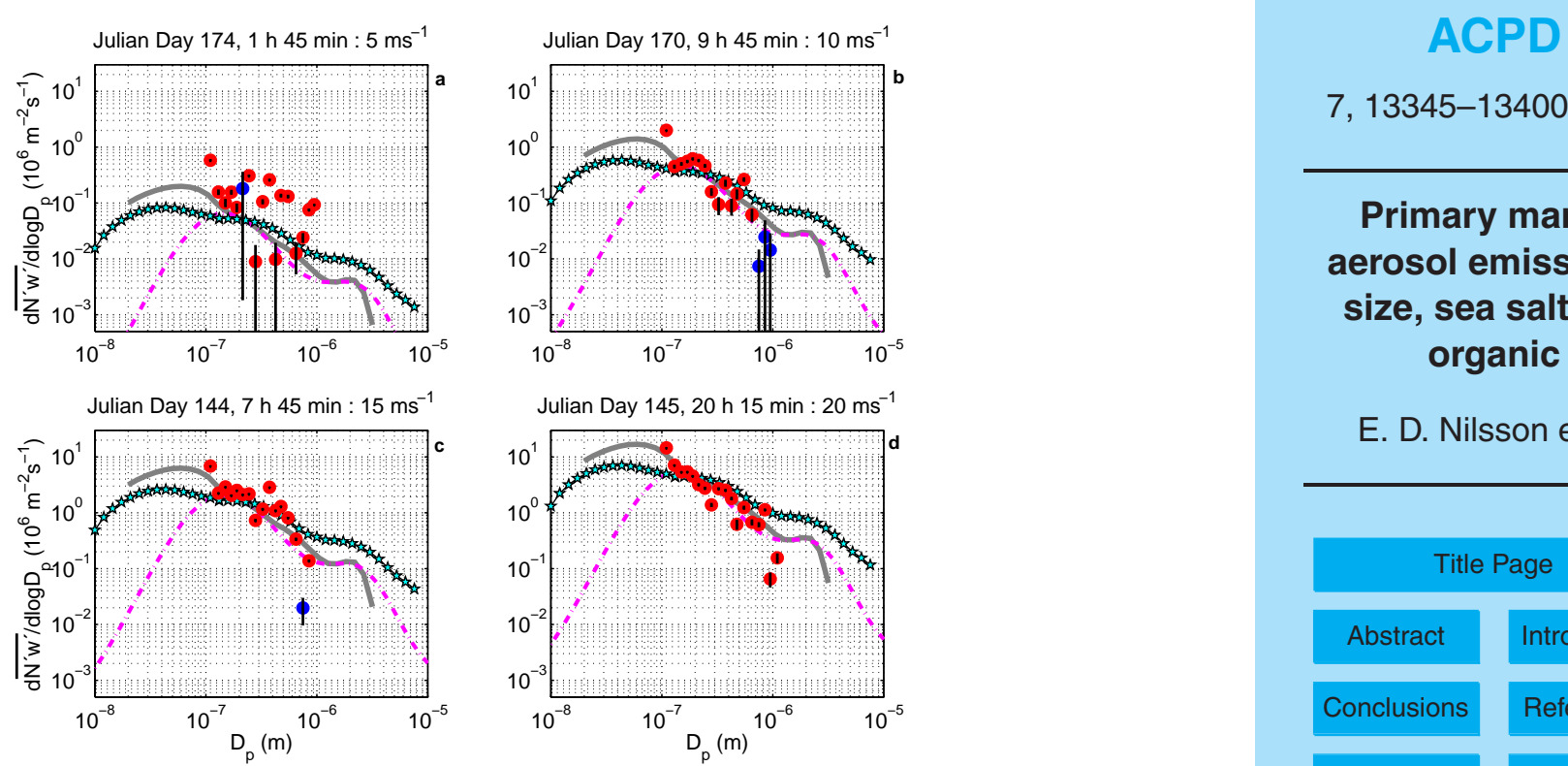

\section{Primary marine aerosol emissions: size, sea salt and organic}

E. D. Nilsson et al.

Fig. 4. (a) Example of sea salt aerosol number flux size distributions from Julian Day 174 based on 30 min of measurements from 01.30 to 02.00 local time (centred around 01.45 ) during which the average wind speed was $5 \mathrm{~ms}^{-1}$. Red circles are upward flux (net emission); blue circles are downward flux (net deposition). Vertical bars are discrete counting error bars. The grey curve is the Mårtensson et al. (2003) parameterisation for the same wind speed. Black curve with light blue stars: The sea salt source parameterisation from Clarke et al. (2006) for the same wind speed. Dashed pink curve: the sea salt source according to Gong (2003) with the tuning parameter $\Theta=22$. (b) Same as (a), but from a half hour sample with an average wind speed of $10 \mathrm{~ms}^{-1}$, Julian Day 170 , centred around 09.45. (c) Same as (a), but from a half hour sample with an average wind speed of $15 \mathrm{~ms}^{-1}$, Julian Day 144, centred around 07.45. (d) Same as (a), but from a half hour sample with an average wind speed of $20 \mathrm{~ms}^{-1}$, Julian Day 145 , centred around 20.15 .

Title Page

Abstract

Introduction

Conclusions

References

Tables

Figures

14

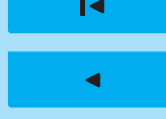

-

Back

Close

Full Screen / Esc

Printer-friendly Version

Interactive Discussion 


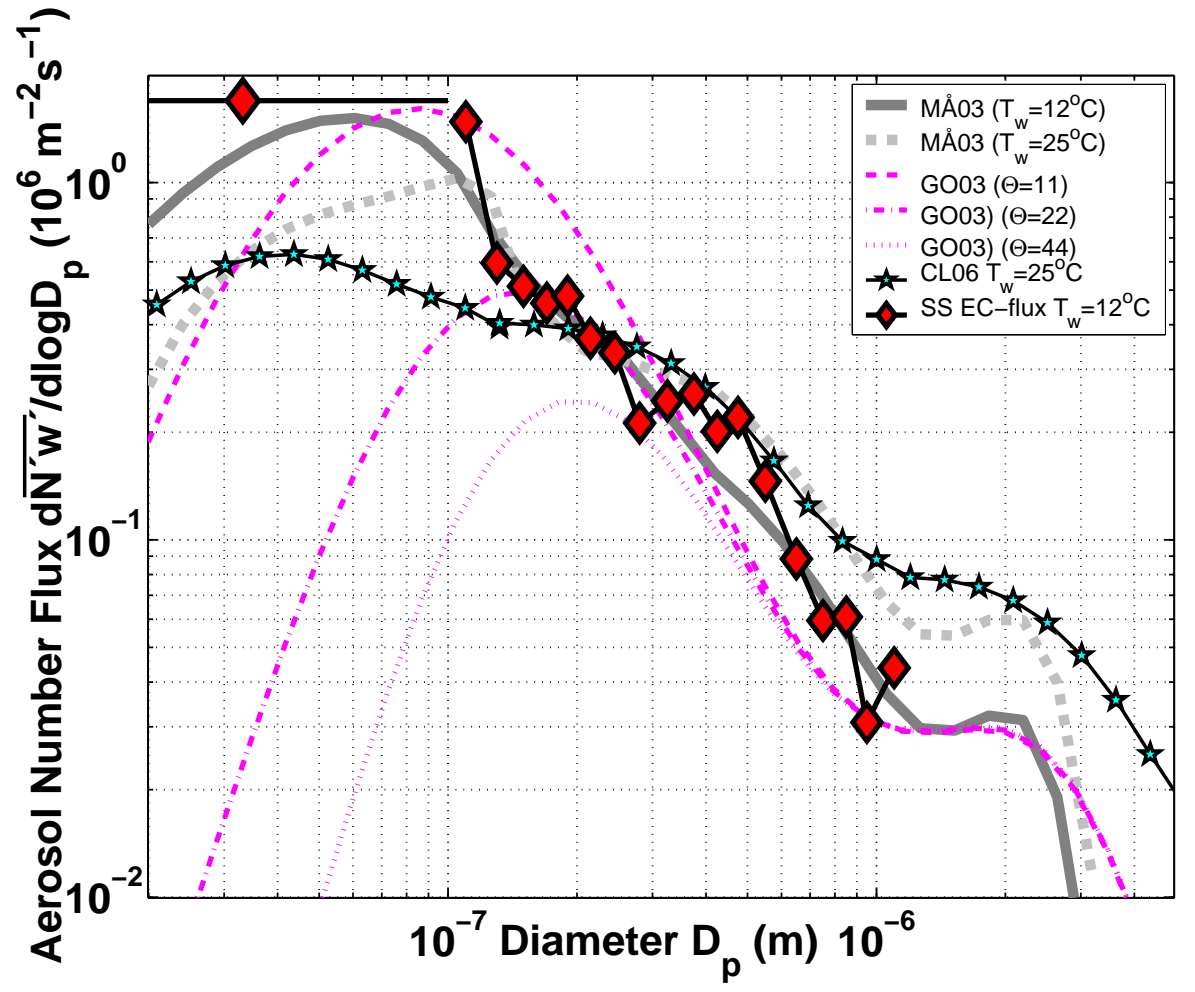

Fig. 5. Aerosol number emission flux size distributions for sea salt per size increment (black curve with red diamonds). The 25 and 75 percentiles of the data are shown for the sea salt fluxes (red dashed curves). Parameterised sea salt number flux according to Mårtensson et al. (2003), based on $T_{w}=12^{\circ} \mathrm{C}$ and the observed median wind speed of $9.8 \mathrm{~ms}^{-1}$ (thick grey curve) and 25 and 75 percentiles (thin full grey curves).

\section{ACPD}

\section{Primary marine aerosol emissions: size, sea salt and organic}

E. D. Nilsson et al.

\section{Title Page}

\section{Abstract}

Conclusions

Tables

14

4

Back

\section{Introduction}

References

Figures

$\rightarrow$

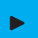

Close

\section{Full Screen / Esc}

Printer-friendly Version

Interactive Discussion 


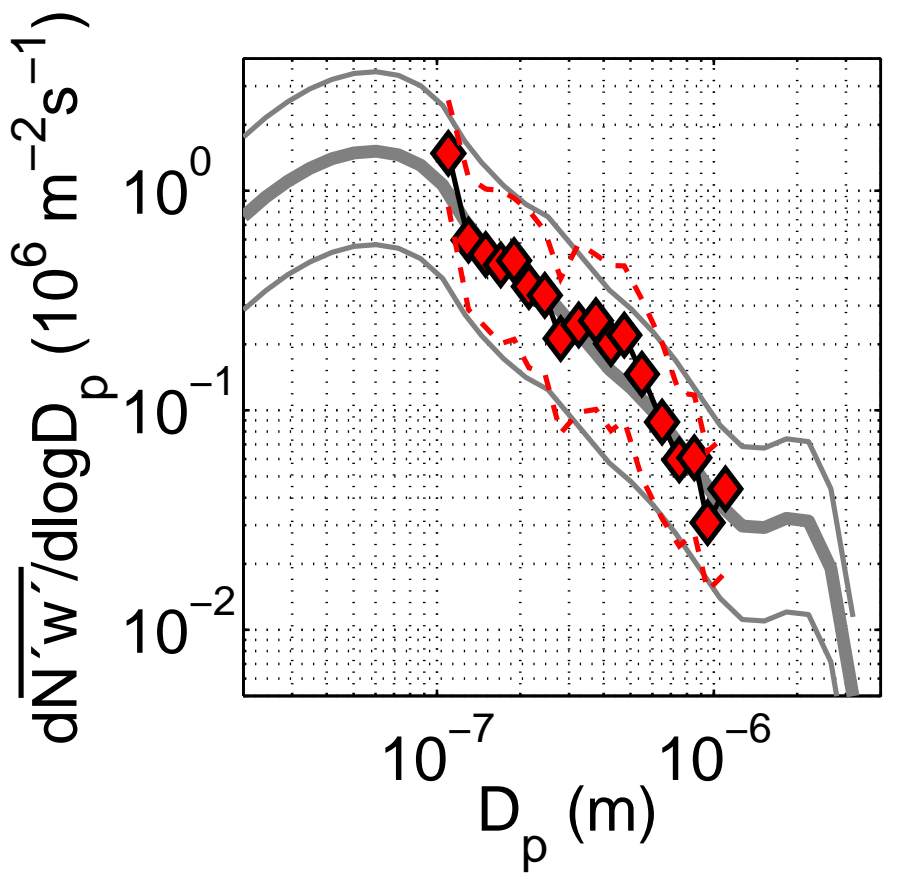

Fig. 6. Comparison of sub micrometer size resolved experimental sea salt emission parameterisations and field data. Aerosol number emission size distributions for sea salt (black curve with red diamonds). Full thick grey curve: Sea salt source parameterisation from Mårtensson et al. (2003) for the sea surface temperature $\left(12^{\circ} \mathrm{C}\right)$ and median wind speed $\left(10.0 \mathrm{~ms}^{-1}\right)$. Black curve with light blue stars: The sea salt source parameterisation from Clarke et al. (2006) for the same median wind speed (the data was collected with a sea surface temperature of $25^{\circ} \mathrm{C}$ ). Thick light dashed grey curve: Sea salt source parameterisation from Mårtensson et al. (2003) for the sea surface temperature $25^{\circ} \mathrm{C}$ and the same median wind speed. Dotted, dotted-dashed, and dashed pink curves: the sea salt source according to Gong (2003) with three different values for the tuning parameter $\Theta(44,22$ and 11).

\section{Primary marine aerosol emissions: size, sea salt and organic}

E. D. Nilsson et al.

\section{Title Page}

\section{Abstract}

Conclusions

Tables

14

4

Back
Introduction

References

Figures

$\rightarrow$

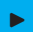

Close

\section{Full Screen / Esc}

Printer-friendly Version

Interactive Discussion 


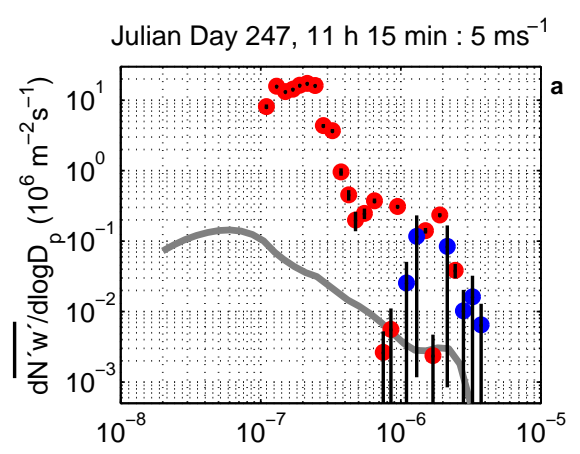

Julian Day 250, 16 h 45 min : $15 \mathrm{~ms}^{-1}$

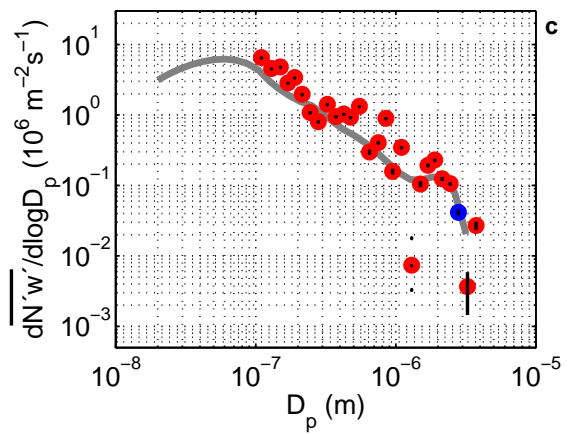

Fig. 7. (a) Example of total aerosol number flux size distributions from Julian Day 247 based on 30 min of measurements from 11:00 to $11: 30$ local time (centred around 11:15) during which the average wind speed was $5 \mathrm{~ms}^{-1}$. Red circles are upward flux (net emission); blue circles are downward flux (net deposition). Vertical bars are discrete counting error bars. The grey curve is the Mårtensson et al. (2003) parameterisation for the same average wind speed. (b) Same as $7 \mathrm{a}$, but from a half hour sample with an average wind speed of $10 \mathrm{~ms}^{-1}$, Julian Day 249 , centred around 03:15. (c) Same as 7a, but from a half hour sample with an average wind speed of $15 \mathrm{~ms}^{-1}$, Julian Day 250, centred around 16:45.

\section{ACPD}

\section{Primary marine aerosol emissions: size, sea salt and organic}

E. D. Nilsson et al.

\section{Title Page}

\section{Abstract}

Conclusions
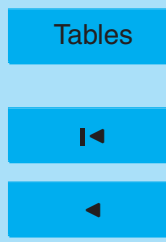

Back

\section{Introduction}

References

Figures

$\rightarrow$

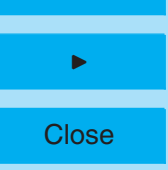

Full Screen / Esc

Printer-friendly Version

Interactive Discussion 


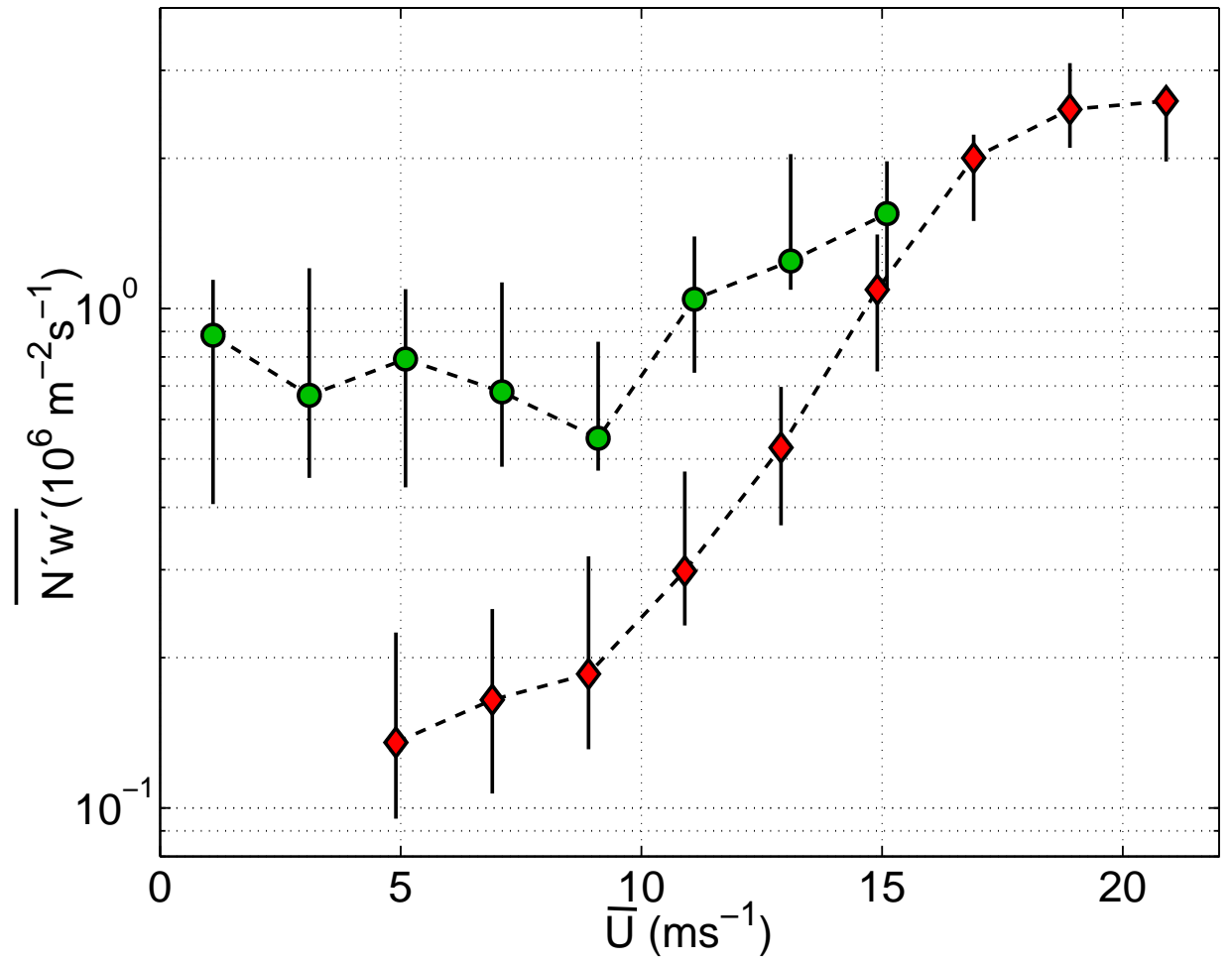

Fig. 8. The median and 25 and 75 percentiles of the total (green circles on black dashed curve) and sea salt (red diamonds on black dashed curve) aerosol number emission fluxes integrated over the full OPC size range and averaged over $2 \mathrm{~ms}^{-1}$ intervals.

\section{$7,13345-13400,2007$}

\section{Primary marine aerosol emissions: size, sea salt and organic}

E. D. Nilsson et al.

\section{Title Page}

\section{Abstract}

Introduction

Conclusions

References

Tables

Figures

14

$\rightarrow$

4

Back

Close

\section{Full Screen / Esc}

Printer-friendly Version

Interactive Discussion 


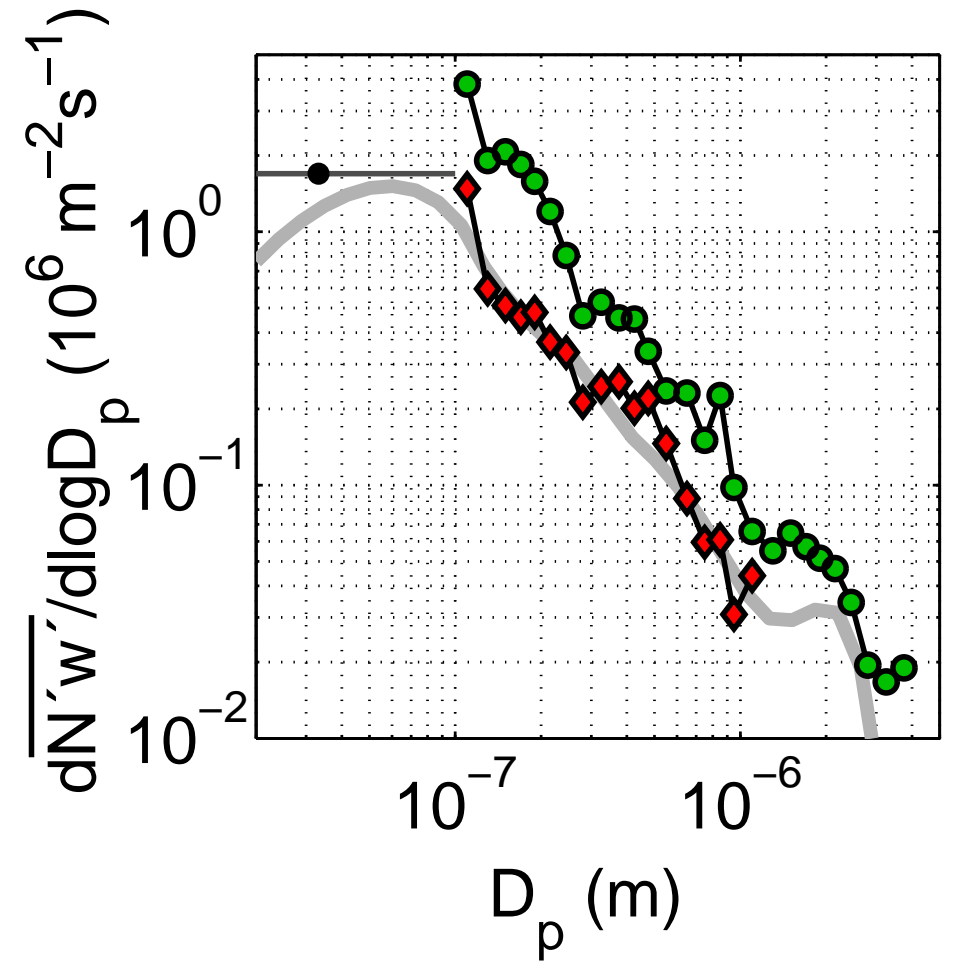

Fig. 9. Median aerosol number emission flux size distributions for the total aerosol (green circles on black curve) and sea salt (red diamonds on black curve). Black circle on black line indicates the average aerosol flux in the $11-110 \mathrm{~nm} D_{p}$ range. Grey curve is the Marrtensson et al. (2003) sea salt source parameterisation for the corresponding median wind speed and water temperature.

\section{ACPD}

\section{Primary marine aerosol emissions: size, sea salt and organic}

E. D. Nilsson et al.

\section{Title Page}

\section{Abstract}

Conclusions

Tables

14

4

Back
Introduction

References

Figures

$\rightarrow$

Close

\section{Full Screen / Esc}

Printer-friendly Version

Interactive Discussion 


\section{ACPD}
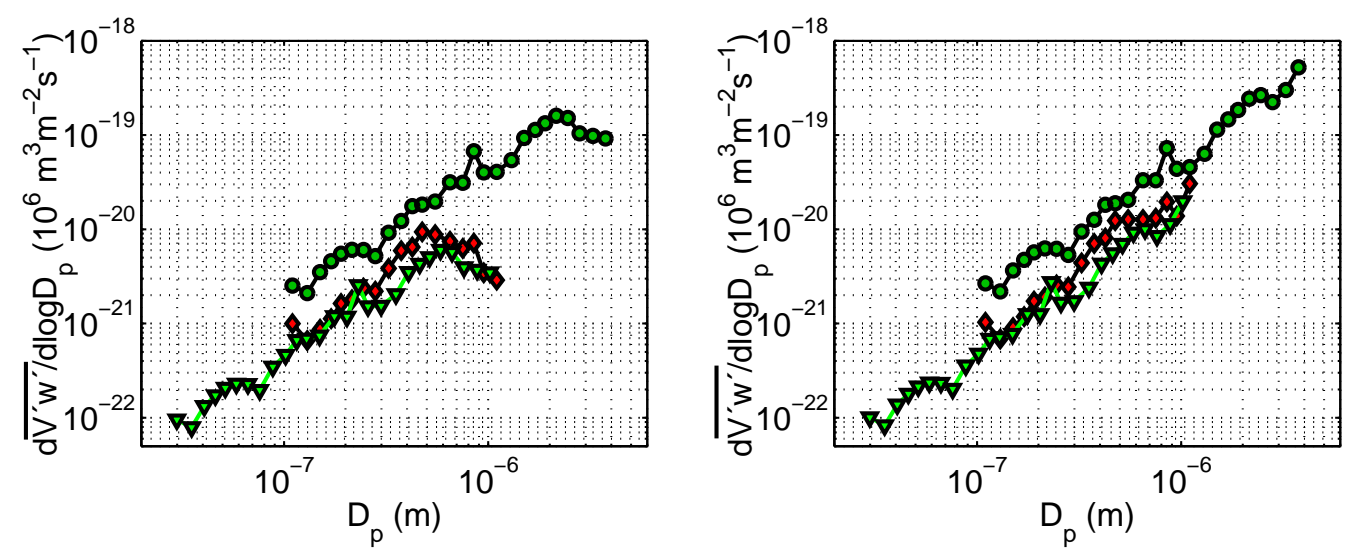

\section{Primary marine aerosol emissions: size, sea salt and organic}

E. D. Nilsson et al.

Fig. 10. (a) Aerosol volume emission median flux size distributions for the total aerosol (black curve with green circles) and sea salt (black curve with red diamonds). The green downwardpointing triangles are the total aerosol flux shifted a factor 3.7 down in diameter and consequently reduced volume flux magnitude, in order to simulate what happen upon heating to $300^{\circ} \mathrm{C}$ if the original total aerosol was an internal mixture of sea salt and semi-volatile (organic) aerosol particles (this curve have been corrected for the difference in median wind speed between sea salt and total aerosol fluxes). Here fluxes are not corrected for the particle losses in the sampling line. (b) Same as (a), but with tube loss correction.

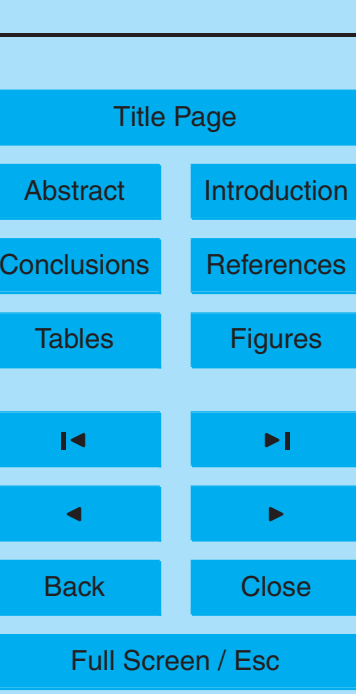

Printer-friendly Version

Interactive Discussion 


\section{ACPD}

\section{7, 13345-13400, 2007}
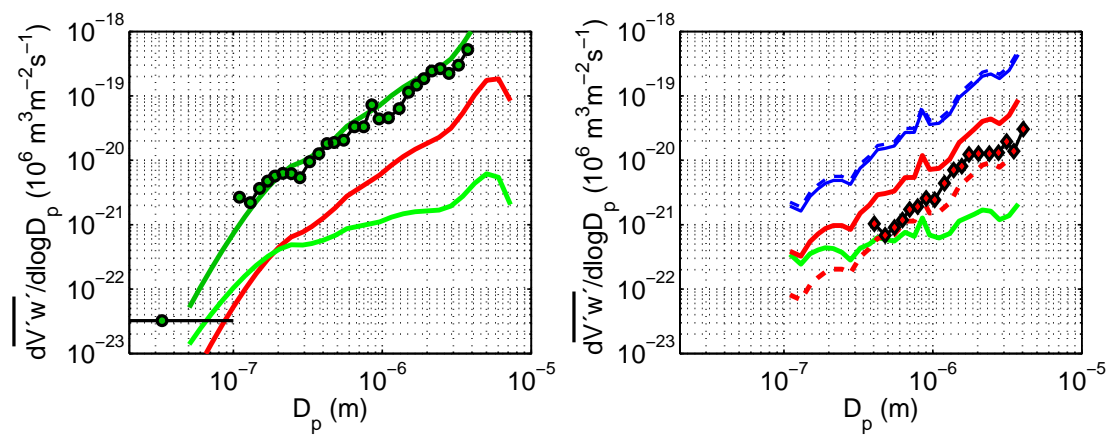

\section{Primary marine aerosol emissions: size, sea salt and organic}

E. D. Nilsson et al.
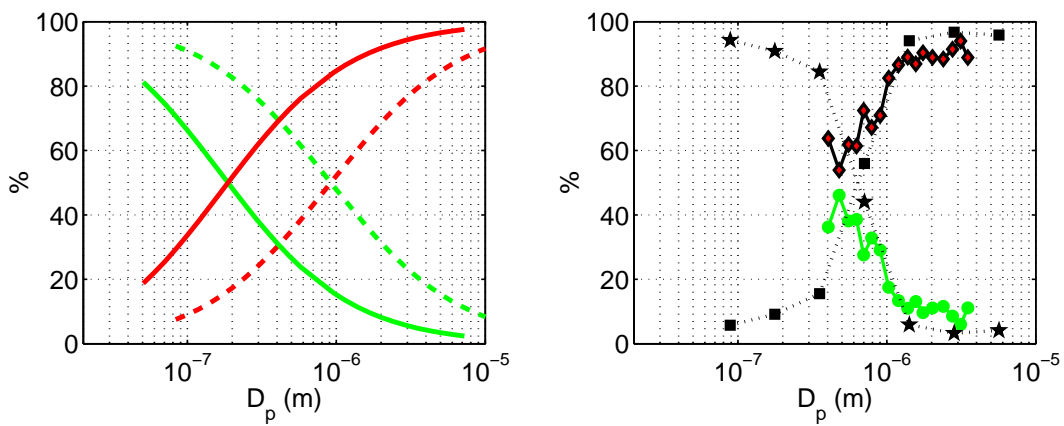

Title Page

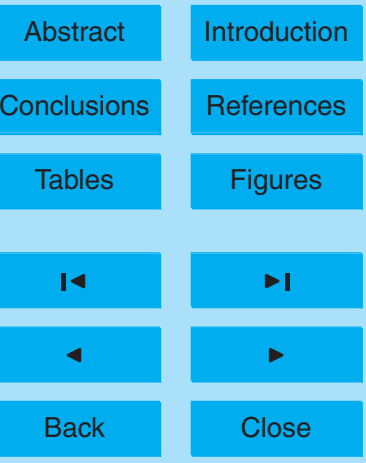

Full Screen / Esc

Fig. 11.

Printer-friendly Version

Interactive Discussion 
Fig. 11. (a) Measured median aerosol volume emission flux size distributions for the total aerosol (black curve with green circles). The red curve is the Mårtensson et al. (2003) sea salt parameterisation for the median wind speed and water temperature but shifted up in size a factor 3.7. The light green curve is the organic carbon aerosol volume emission according to Ellison et al. (1999). The green curve is the total aerosol volume emission (including water+sea salt+water insoluble organic carbon) that results from the combined Ellison et al. (1999) and Mårtensson et al. (2003) model using a brine salinity of $16.6 \%$. (b) The organic carbon (green) and sea salt (red) of the total aerosol (minus water) according to the model calculations in Fig. 11a. Dashed curves are the same, but for a brine salinity of $3.5 \%$. (c) Blue curves are the water aerosol volume flux broken up from the observed total aerosol median emissions (as seen in Fig. 11a) using Ellison et al. (1999) for brine salinities of $16.6 \%$ (full curve) and $3.5 \%$ (dashed curve). Similarly the red curves are the sea salt fraction and the green curve is the organic carbon. The red diamonds on a black curve are the measured median sea salt aerosol emission fluxes. (d) Red diamonds on black curve is the sea salt fraction of the total aerosol volume flux (minus water) and the green circles on a green curve are the corresponding organic carbon fraction, using the measured median total and sea salt aerosol volume fluxes and the Ellison et al. (1999) model. Black five-point stars on a dotted black curve and the black squares on a dotted black curve are the ratio of organic carbon and sea salt mass, respectively, to the sum of these fractions from Fig. 2 in Cavalli et al. (2004).

\section{Primary marine aerosol emissions: size, sea salt and organic}

E. D. Nilsson et al.

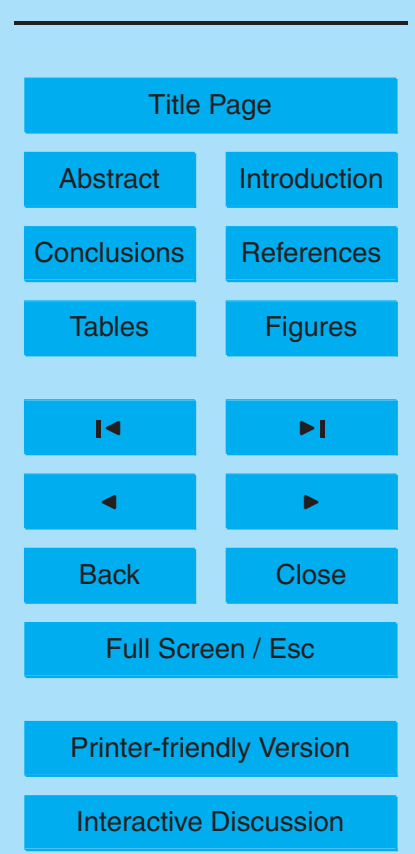

